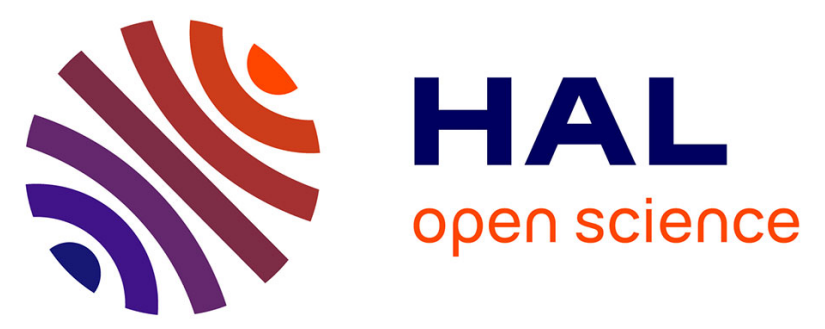

\title{
Mice with muscle-specific deletion of Bin1 recapitulate centronuclear myopathy and acute downregulation of dynamin 2 improves their phenotypes
}

Roberto Silva-Rojas, Vasugi Nattarayan, Francisco Jaque-Fernandez, Raquel Gomez-Oca, Alexia Menuet, David Reiss, Marie Goret, Nadia Messaddeq, Valentina M Lionello, Christine Kretz, et al.

\section{To cite this version:}

Roberto Silva-Rojas, Vasugi Nattarayan, Francisco Jaque-Fernandez, Raquel Gomez-Oca, Alexia Menuet, et al.. Mice with muscle-specific deletion of Bin1 recapitulate centronuclear myopathy and acute downregulation of dynamin 2 improves their phenotypes. Molecular Therapy, 2021, 10.1016/j.ymthe.2021.08.006 . hal-03374920

\author{
HAL Id: hal-03374920 \\ https://hal.science/hal-03374920
}

Submitted on 12 Oct 2021

HAL is a multi-disciplinary open access archive for the deposit and dissemination of scientific research documents, whether they are published or not. The documents may come from teaching and research institutions in France or abroad, or from public or private research centers.
L'archive ouverte pluridisciplinaire HAL, est destinée au dépôt et à la diffusion de documents scientifiques de niveau recherche, publiés ou non, émanant des établissements d'enseignement et de recherche français ou étrangers, des laboratoires publics ou privés. 
Mice with muscle-specific deletion of $\operatorname{Bin} 1$ recapitulate centronuclear myopathy and acute downregulation of dynamin 2 improves their phenotypes

Roberto Silva-Rojas $^{1 \#}$, Vasugi Nattarayan ${ }^{1 \#}$, Francisco Jaque-Fernandez ${ }^{2}$, Raquel Gomez-Oca ${ }^{1,3}$, Alexia Menuet ${ }^{1}$, David Reiss ${ }^{1}$,Marie Goret ${ }^{1}$, Nadia Messaddeq ${ }^{1}$, Valentina M. Lionello ${ }^{1}$, Christine Kretz $^{1}$, Belinda S. Cowling ${ }^{1,3}$, Vincent Jacquemond ${ }^{2}$, Jocelyn Laporte ${ }^{1^{*}}$

${ }^{1}$ Institut de Génétique et de Biologie Moléculaire et Cellulaire (IGBMC), CNRS UMR7104, INSERM U1258, Université de Strasbourg, 67404 Illkirch, France

${ }^{2}$ Univ Lyon, Université Claude Bernard Lyon 1, CNRS UMR5310, INSERM U1217, Institut NeuroMyoGène, 69373 Lyon, France

${ }^{3}$ Dynacure, 67404 Illkirch, France

${ }^{\#}$ Contributed equally to this work

*To whom correspondence may be addressed: Jocelyn Laporte; Email: jocelyn@igbmc.fr

Keywords: myopathy, antisense oligonucleotides, membrane curvature, dynamin, amphiphysin, therapy

Short title: Pathology and improvement of BIN1 myopathy 


\begin{abstract}
Mutations in the BIN1 (Bridging Interactor 1) gene, encoding the membrane remodeling protein amphiphysin 2, cause centronuclear myopathy associated with severe muscle weakness and myofiber disorganization and hypotrophy. There is no available therapy, and the validation of therapeutic proof-of-concepts is impaired by the lack of a faithful and easy-to-handle mammalian model. Here, we generated and characterized the Binl $1^{\text {mck-l- }}$ mouse through Binl knockout in skeletal muscle. Binl ${ }^{\text {mck-/ }}$ mice were viable, unlike the constitutive Binl knockout, and displayed decreased muscle force and most histological hallmarks of centronuclear myopathy including myofiber hypotrophy and intracellular disorganization. Notably, Bin1 $1^{\text {mck-l- }}$ myofibers presented strong defects in mitochondria and T-tubule networks associated with deficient calcium homeostasis and excitation-contraction coupling at the triads, potentially representing the main pathomechanisms. Systemic injection of antisense oligonucleotides targeting Dnm2 (Dynamin 2) that codes for dynamin 2, a BIN1 binding partner regulating membrane fission and mutated in other forms of centronuclear myopathy, improved muscle force and normalized the histological Bin1 ${ }^{\text {mck-/ }}$ phenotypes within 5 weeks. Overall, we generated a faithful mammalian model for centronuclear myopathy linked to BIN1 defects, and validated Dnm2 antisense oligonucleotides as a first translatable approach to efficiently treat BIN1-centronuclear myopathy.
\end{abstract}




\section{Introduction}

A plethora of muscle diseases impair different steps of muscle formation or maintenance. Centronuclear myopathies (CNM) are rare genetic diseases associated with a severe generalized muscle weakness associated with myofiber hypotrophy and premature death. ${ }^{1,2}$ The name reflects the typical intracellular disorganization of myofibers with organelle mis-positioning including the centralization of nuclei that are normally present at the periphery of muscle fibers. ${ }^{3,4}$ In addition, myofibers are smaller, rounder or heterogeneous in size. Despite the significant impact on morbidity and mortality, to date there is no specific therapy available for CNM patients.

CNM can be due to mutations in either MTM1, DNM2, BIN1 or SPEG genes, while mutations in additional genes as RYRI, TTN, CACNA1S, ZAK and PYROXDI combine CNM features with other histological defects. ${ }^{5-7}$ Of note, several of these gene products directly regulate excitationcontraction coupling at the skeletal muscle triad (RYR1, CACNA1S/Ca 1.1 ) or membrane remodeling (BIN1, DNM2), leading to the hypothesis that defects in triad structure and function form a common disease cause. ${ }^{8}$

BIN1 encodes amphiphysin 2, a protein sensing and controlling membrane curvature through its N-BAR (N-amphipathic Bin/Amphiphysin/Rvs) domain and recruiting through its SH3 (Src Homology) domain effectors like dynamins (DNM1 and DNM2) which tubulate and potentially fission membranes. ${ }^{9}{ }^{10}$ While BIN1 is not the most frequent gene mutated in CNM, it is mutated in both dominant and recessive forms. ${ }^{11,12}$ Moreover, a founder mutation leads to a potentially high prevalence in the Roma population (also known as Gypsies) that is the most numerous ethnic minority in Europe with an estimated population of 11 million. ${ }^{13}$ BIN1 mutations either modify the N-BAR domain leading to decreased membrane tubulation, or truncate or extend the SH3 domain altering the binding to DNM2. ${ }^{12,14}$

Regarding the understanding and treatment of BIN1-CNM, the two main bottlenecks are the absence of a faithful and easy-to-handle mammalian model and the lack of therapeutic proof-ofconcept necessary to trigger clinical development.

A drosophila mutant for Amph, the BIN1 ortholog, is flightless with severe structural defects of the triads, the structural basis of excitation-contraction coupling formed by a T-tubule contacting 2 terminal cisternae of sarcoplasmic reticulum (SR). ${ }^{15}$ Downregulation of binl with antisense 
morpholino in zebrafish led to myofiber disorganization with centralized nuclei and structural and functional defects of the triads. ${ }^{16}$ A spontaneous dog model was found with a splice mutation of the muscle-specific exon 11 of BIN1 and muscle atrophy, myofibers with centralized nuclei and radial organization of the sarcoplasmic reticulum. ${ }^{17}$ In mice, constitutive Binl knockout presented embryonic or perinatal lethality probably due to feeding defects. ${ }^{18,}{ }^{19}$ Similarly, such lethal phenotype was reproduced in a skeletal muscle specific knockout using the Cre recombinase under the control of the human skeletal actin (HSA) promoter. ${ }^{18,20}$ Conversely, knockout of the musclespecific exon 11 led to viable mice that did not display CNM phenotypes. ${ }^{20}$ Acute reduction of Binl with shRNA in adult mice however showed disruption of the triad structure linked to alterations of intracellular $\mathrm{Ca}^{2+}$ release. ${ }^{21}$

Some potential therapies for centronuclear myopathies have been proposed. ${ }^{22}$ Moreover, downregulation of Dnm2 with antisense oligonucleotides was shown to efficiently ameliorate the

skeletal muscle phenotype in MTM1- and DNM2-CNM mouse models, ${ }^{23,}{ }^{24}$ an approach that is currently in clinical trials (NCT04033159). However, it was never tested for BIN1-CNM due to lack of a faithful viable mouse model, albeit genetic crosses recently suggested that decreasing Dnm2 prevent the neonatal death of Binl knockout mice. ${ }^{18}$

Here, we generated and characterized a viable Binl knockout mouse faithfully reproducing most motor, histological and structural hallmarks of CNM, and validated Dnm2 antisense oligonucleotides as a first translatable approach to efficiently cure this model.

\section{Results}

\section{Generation of a viable muscle-specific Bin1 knockout mouse with decreased muscle force.}

To generate a viable mouse model without Binl expression in muscle, we crossed mice floxed for Binl exon 20 (Bin $1^{f l f l}$ ) with Binl heterozygous mice (Bin1 $1^{m c k+-}$ ) expressing the Cre recombinase under the control of the muscle creatine kinase promoter (MCK-Cre) that expresses from 17 days post-coitum (dpc) (Fig. 1A). In comparison, the HSA promoter used to obtain perinatal lethal mice

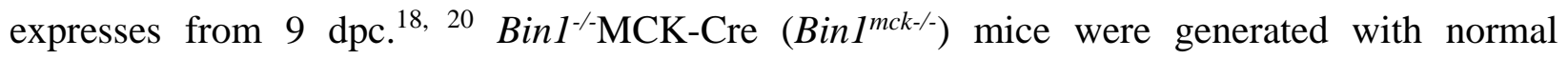
Mendelian ratio and were viable to at least 12 months of age (Fig. 1B-C), the maximum age analyzed in this study. RT-qPCR confirmed the absence of Bin1 mRNA levels in Bin1 ${ }^{m c k-/}$ tibialis 
anterior (TA) muscle and western blot revealed the absence of BIN1 from Bin1 ${ }^{\text {mck-/- }}$ animals at 8 weeks of age (Fig. 1D-E).

Binl ${ }^{\text {mck-l- }}$ mice did not present differences in body or muscle weight at 8 weeks while body weight was reduced at 4 months and 12 months, and TA weight ratio was reduced at 4 months only (Fig. $1 \mathrm{~F}$ and S1). Hanging capability until 8 weeks of age, endurance and fatigue in treadmill at 4 months, and performances in the string test and rotarod test at 6-7 weeks of age was comparable between Binl ${ }^{f l f}$ and Binl ${ }^{m c k-/}$ animals, suggesting normal locomotor coordination (Fig. S2A-E). For phenotypical and histological studies, we used TA as this muscle is commonly affected in other CNM mouse models. ${ }^{25-27}$ We quantified the TA muscle force in situ following sciatic nerve

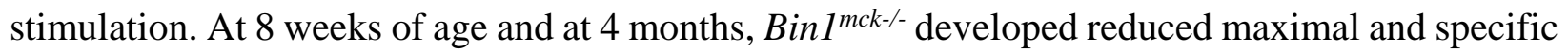
force compared to controls. While Bin $1^{f l f l}$ mice at 8 weeks of age reached an average specific force of $18 \mathrm{mN} / \mathrm{mg}$, Binl $1^{\text {mck-/ }}$ mice only produced a specific force of $10.6 \mathrm{mN} / \mathrm{mg}$, a $41 \%$ reduction (Fig. $1 \mathrm{G}$ and S2F). Analysis at different stimulation frequencies revealed a clear reduction at several frequencies tested in 8 weeks and 4 months old animals (Fig. 1H and S2G-J). Therefore the absence of BIN1 didn't have a significant impact on the overall locomotor abilities while it clearly affected the muscle force at 8 weeks and 4 months of age.

\section{Bin1 $^{\text {mck-/- }}$ mice develop most of the histological hallmarks of centronuclear myopathy.}

We further assessed the presence of CNM features at the histopathological level. Staining of Bin1 ${ }^{\text {mck-l- }}$ TA sections revealed the presence of darker hematoxylin eosin (HE) staining in the center of the fibers that were enriched in mitochondrial oxidative activity as stated in SDH and NADH staining while Gomori staining remained normal at 8 weeks (Fig. 2A and S3A). Similar defects in HE and SDH staining were observed in 4 months and 12 months TA from Binl ${ }^{\text {mck-/ }}$ mice (Fig. S3B-G). The gastrocnemius presented with similar histological defects as observed in the TA, while heart histology didn't reveal any obvious defect at 8 weeks of age (Fig. S4A). Heterozygous knockout animals (Bin ${ }^{m c k+/-}$ ) didn't present any histological defect in TA, showing total reduction of Binl is required to generate the histological phenotype and confirming this is a model for recessive BIN1-CNM (Fig. S4B). Bin1 ${ }^{m c k-/-}$ TA presented smaller fibers and a strong reduction in the number of large fibers when compared to Bin $1^{f l f}$ controls at 8 weeks, 4 months and 12 months

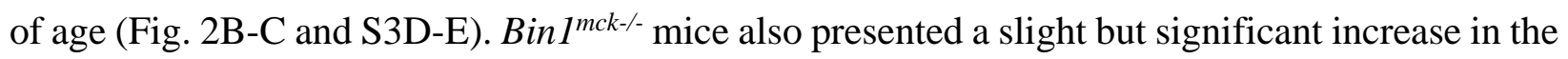
percentage of fibers with high circularity at 8 weeks of age (Fig. 2D). The decrease in large fibers 
at 8 weeks of age was in line with the reduction of fast-twitch IIb fibers and the slight but not significant increase in type I fibers (Fig. S4C). Binl ${ }^{m c k-/}$ did not present increased nuclear centralization at 8 weeks of age but the rate of TA fibers with internalized nuclei increased in 4 months and particularly in 12 months old Binl ${ }^{\text {mck-/ }}$ mice (Fig. 2E, S3B and S3F). Of note, the $D n m 2^{\mathrm{RW} /+}$ mouse mimicking the most common R465W mutation found in DNM2-CNM also displays CNM hallmarks but has normal nuclei positioning at 8 weeks. ${ }^{28}$ Altogether, Bin ${ }^{\text {mck-/- }}$ mice display muscle weakness and most of the histological hallmarks of CNM, highlighting the relevance of Bin1 ${ }^{\text {mck-/- }}$ mice as a model for BIN1-CNM.

\section{Bin1 $^{\text {mck-/- }}$ myofibers display mitochondria disorganization.}

To better characterize the pathomechanism linked to the defects in muscle force and histology in Bin $1^{m c k-/}$ mice, we performed electron microscopy on TA muscles and found a general intracellular disorganization with altered sarcomere width and spacing (Fig. 3A). Nuclei position and shape were normal. Local accumulations of mitochondria were observed, together with increased prohibitin protein levels, an inner mitochondrial membrane protein that also presented a central and sub-sarcolemma accumulation pattern in Binl ${ }^{m c k-/}$ mice (Fig. 3B, C and S5A). To determine the cause of mitochondrial accumulation, mitochondrial biogenesis and removal were assessed. mRNA levels from the mitochondrial biogenesis master regulator Ppargcla were comparable between Bin $1^{m c k-/-}$ and Bin $1^{f l f l}$ mice (Fig. 3D). In Bin $1^{m c k-/-}$ muscles, electron microscopy revealed autophagosomes in regions where mitochondria accumulated and LC3 immunofluorescence showed increased accumulation of LC3-positive dots (Fig. 3E). In line with this, the protein expression level of P62 and lipidated LC3 were slightly, albeit not significantly, increased in

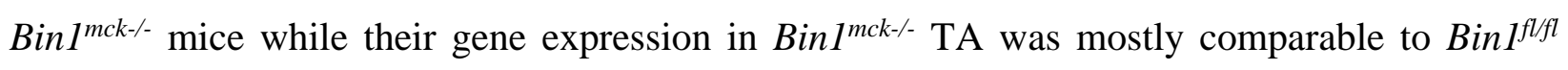
littermates (Fig. 3F, G and S5B-C), suggesting mild defects in mitochondrial positioning consistent with mitochondria accumulation. Therefore, the muscle weakness observed in Binl ${ }^{\text {mck-/- }}$ muscles may arise in part from sarcomere and mitochondria disorganization.

\section{Bin1 $^{\text {mck-l- }}$ myofibers present abnormal T-tubules and deficient excitation-contraction coupling.}

BIN1 is a key player in the biogenesis of T-tubule in skeletal muscle. ${ }^{10,15}$ To better understand the decreased muscle force observed in Binl ${ }^{m c k-/}$ mice, T-tubules were imaged and excitationcontraction coupling assessed in isolated muscle fibers from flexor digitorum brevis (FDB), a 
muscle from which intact isolated fibers can be easily obtained. While Bin $1^{\text {mck-l }}$ FDB histology is similar to Bin $1^{f l f l}$ littermates at 8 weeks of age (Fig. S6A-B), di-8-anneps staining of plasma membrane invaginations revealed an altered network and a decreased density of T-tubules in isolated Binl ${ }^{m c k-1}$ fibers (Fig. 4A-B). The $\mathrm{Ca}^{2+}$ current through the T-tubule Cav1.1 $\mathrm{Ca}^{2+}$ channel/voltage sensor and the release of SR $\mathrm{Ca}^{2+}$ through RYR1 channels were simultaneously detected in isolated fibers under voltage-clamp conditions (Fig. 4C-H). The Cav1.1 current density was smaller in the Bin $1^{m c k-/}$ fiber, accompanied by an increased residual leak component visible in response to the lowest amplitude pulses (Fig. 4C). Mean values for the voltage dependence of the peak current in the two groups are reported in Figure 4D. In each fiber the voltage dependence was fitted by the standard equation plus a linear outward component. Mean values from the fits revealed that the maximum conductance of the Cav1.1 channel population in the Bin $1^{\text {mck-l }}$ fibers was reduced by $\sim 30 \%$ and as compared to the mean value in Binl $1^{f l f l}$ fibers (Fig. 4E), while corresponding mean values for the apparent reversal potential (Fig. 4E), and for the half-activation voltage and steepness factor did not statistically differ between the two groups (Fig. S6C). The effect on the conductance was paralleled by a slight while not significant increase in the residual outward leak current (slope) in the Bin $1^{m c k-/}$ fibers (Fig. 4E) indicating that besides affecting Cav1.1 channels, another conductance component of the plasma membrane may be affected. Rhod-2 $\mathrm{Ca}^{2+}$ transients from Bin ${ }^{\text {mck-/ }}$ fibers exhibited a reduced peak amplitude as compared to Bin $1^{f l f l}$ fibers (Fig. 4F). The rate of $\mathrm{SR} \mathrm{Ca}^{2+}$ release calculated from the rhod-2 transients indicated that the mean value for maximum rate was reduced by almost $60 \%$ (Fig. 4G-H) in the Binl ${ }^{\text {mck-l- }}$ fibers while values for the mid-activation voltage and steepness factor were unaffected (Fig. S6D). Overall, myofibers lacking BIN1 have an abnormal T-tubule network and a strong defect in excitation-contraction coupling, correlating with decreased muscle force.

\section{Dnm2 downregulation improves the force production of $B i n 1^{m c k-/-}$ mice.}

Our previous studies suggested BIN1 is a negative regulator of DNM2 in muscle, as decreasing Dnm2 through genetic cross prevented the neonatal death of Binl $1^{-/}$mice. ${ }^{18}$ We took advantage of the Binl $1^{m c k-1}$ mice as a viable and faithful BIN1-CNM model to test a therapeutic approach by injecting antisense oligonucleotides (ASO) targeting Dnm2. We selected a dose of $25 \mathrm{mg} / \mathrm{kg}$ that was previously validated as the safest and most efficient dose in other CNM mouse models. ${ }^{24,25 \text {, }}$ ${ }^{27}$ Bin $1^{\text {mck-r }}$ muscles presented a slight increase in DNM2 protein and RNA levels (Fig. 5A-B and 
S7A). Dnm2 ASO treatment clearly reduced Dnm2 mRNA and protein levels in both ASO-treated Binl $f^{f l f l}$ and Bin $1^{\text {mck-l }}$ mice (Fig. 5B-C and S7B). While the muscle force of PBS-treated Binl ${ }^{\text {mck-l- }}$ mice was significantly different from the one of PBS-treated Bin $f^{f l f l}$ mice, Dnm2 downregulation slightly increased the muscle force of ASO-treated Binl ${ }^{m c k-/}$ mice to a level not significantly different from the ASO-treated Bin $f^{f l f l}$ controls (Fig. 5D and S8A). At low stimulation frequencies $(1,25$ and $50 \mathrm{~Hz})$, the force produced by ASO-treated Bin $1^{m c k-l-}$ mice was comparable to the ASOtreated Binl ${ }^{f l f l}$ controls and significantly increased compared to PBS-treated Bin $1^{\text {mck-l- }}$ mice (Fig. 5E). Overall, Dnm2 downregulation increases the force production of ASO-treated Bin $1^{m c k-l-}$ mice.

\section{Dnm2 downregulation improves the CNM histological hallmarks of Bin1 ${ }^{m c k-/}$ mice.}

As Dnm2 downregulation increased muscle force production of Bin $1^{m c k-/}$ muscle, we then assessed rescue at the histopathological level. The Dnm2 ASO treatment fully normalized the central accumulations of mitochondrial oxidative activity observed in HE, SDH and NADH stainings of Bin $1^{\text {mck-r- }}$ muscle sections, further confimed by mitochondrial TOMM20 immunofluorescence (Fig. 6A-B and S8B-D) Moreover, desmin, an essential regulator of myofibril integrity, with aberrant localization in MTM1-CNM patients and mice, ${ }^{29,30}$ is mislocalized in the center of PBStreated Bin $1^{m c k-l-~ f i b e r s ~ a n d ~ i t s ~ l o c a l i z a t i o n ~ i s ~ f u l l y ~ r e s t o r e d ~ i n ~ A S O-t r e a t e d ~ B i n l ~}{ }^{m c k-/}$ mice (Fig. S8C-D). While myofibers from the PBS-treated Bin $1^{\text {mck-l- }}$ mice were smaller compared to Bin $1^{f l f l}$ controls , Dnm2 ASO treatment normalized fiber size distribution and the percentage of large fibers (Fig. 6C-E). Correlating with the effect on large fibers, a slight but not significant decrease in $M y h 7$ mRNA levels (specific for type I fiber) and increase of Myh4 mRNA levels (type IIb fiber) was noted in ASO treated Bin $1^{\text {mck-l }}$ muscles compared to PBS treated Bin $1^{m c k-/}$ muscles (Fig. S8E). Altogether, Dnm2 downregulation improved both motor function and the CNM histological hallmarks of Binl ${ }^{\text {mck- }-}$ mice, highlighting Dnm2 ASO treatment as an efficient injectable therapeutic approach to treat recessive BIN1-CNM.

\section{Discussion}

In this study, we generated and characterized the Bin $1^{\text {mck-l- }}$ mouse as a first viable mammalian model reproducing most signs of BIN1-CNM. It provided a unique opportunity to test a potential treatment. Dynamin 2 is a binding partner of BIN1 and also mutated in CNM. Injection of antisense 
oligonucleotides targeting Dnm2 led to about 50\% reduction in dynamin 2 compared to PBStreated mice of the same genotype, and to the improvement of motor and histopathological phenotypes of the Bin $1^{m c k-/}$ mice. In these experiments, dynamin 2 levels in both ASO-treated genotypes are below the baseline of PBS-treated Binl ${ }^{f l f l}$ mice. These results provide novel insights in the role of BIN1 in skeletal muscle and validate a therapeutic proof-of-concept.

$B i n 1^{\text {mck-/ }}$ mice represent a faithful model for autosomal recessive BIN1-CNM with a clear decrease in muscle force, and most histological hallmarks as smaller and rounder myofibers with typical central accumulation of oxidative activity and a general intracellular disorganization. Alteration of the T-tubule network and the strong defect in excitation-contraction coupling most probably explain the decreased muscle force. However, such defects appear compatible with a conserved locomotor activity and survival into adulthood. In contrast to the neonatal lethality observed when Binl was deleted using Cre recombinase under the control of CMV or HSA promoters, ${ }^{18,}{ }^{19,} 31$ Bin1 $1^{m c k-/}$ mice are viable and fertile and display a disease onset similar to patients, making this model suitable for the establishment of treatment protocols.

BIN1-CNM patients present high rates of fibers with centralized nuclei while Bin1 ${ }^{\text {mck-/ }}$ mice only display increased nuclear internalization at 12 months of age and not at 8 weeks, ${ }^{12}$ suggesting progressive deterioration of muscle morphology in Bin1 ${ }^{m c k-/}$ mice. Similarly, in the mouse models for DNM2-CNM, ${ }^{27,28}$ the abnormal nuclei centralization seen in patients is not reproduced. Indeed, centronucleation might be an easier-to-see manifestation of the same problem that causes mislocalization of other organelles in these disorders Furthermore, the percentage of centralized nuclei in CNM patients is highly variable and does not correlate with disease severity. ${ }^{32} \mathrm{~A}$ few studies linked centronucleation to muscle pathology. ${ }^{33}$ However, centronucleation during muscle regeneration does not lead to $\mathrm{CNM}$, and muscle weakness is not often associated to central nuclei (e.g. nemaline myopathy). Therefore, the strong EC coupling defects observed in Bin1 ${ }^{\text {mck-/- }}$ muscles is sufficient to cause the myopathy. Yet, several lines of evidence support the direct role of BIN1 in nuclei positioning. In particular, BIN1 controls nuclei and triad position with N-WASP in myofibers differentiated in vitro. ${ }^{34}$ Moreover, BIN1 links the nuclear envelope protein nesprin to both actin and microtubules cytoskeleton to locate nuclei in C. elegans seam cells. ${ }^{35}$ Altogether it suggests that BIN1 and DNM2 may be less important for nuclei position in mice than in human. 
Conversely, BIN1 loss strongly alters mitochondria positioning in muscle, leading to accumulation of mitochondria in the center of myofibers as typically seen in patients. ${ }^{3}$

T-tubules start forming at around $14 \mathrm{dpc}$ in mouse embryo and reach their final orientation soon after birth. ${ }^{36}$ Deleting Binl with the HSA promoter expressing from 9 dpc lead to perinatal death, ${ }^{18}$ while using the MCK promoter expressing from $17 \mathrm{dpc}$ is compatible with survival into adulthood. In addition, both the intramuscular injection of shRNA or U7 small nuclear RNA targeting Binl expression or splicing, respectively, in adult mice lead to structural T-tubule defects and alteration of intracellular $\mathrm{Ca}^{2+}$ release. ${ }^{21,37}$ Altogether, it suggests BIN1 is a major protein for T-tubule biogenesis, as proposed in differentiating muscle cells and in cardiac muscle. ${ }^{10,38,39} \mathrm{BIN} 1$ has also an important role in T-tubule maintenance in adult. Noteworthy, decreasing DNM2 by about $50 \%$ in $B$ in $1^{-1}$ mouse through a genetic cross led to normal T-tubule and intracellular myofiber structure. ${ }^{18}$ Similarly, as shown here, decreasing DNM2 by about 50\% in Bin $1^{\text {mck-l- }}$ mouse with antisense oligonucleotides led to normal oxidative staining, fiber size and morphology, and increased muscle force. Hence, it is still unknown how T-tubules can form and/or maintain without BIN1. Either the BIN1-DNM2 balance is the major regulator, or DNM2 alone or with another BAR protein could control T-tubule biogenesis and maintenance.

Here, amelioration all of the phenotypes tested correlate with the decrease of DNM2 protein levels. Decreasing DNM2 in a time window from 3 to 8 weeks partially improved muscle force defects while fully rescuing organelle mispositioning of Binl $1^{\text {mck-l }}$ muscle fibers. This treatment period corresponds to the childhood to early adulthood transition, when most BIN1-CNM patients are affected. It supports that DNM2 may be overactive in muscle lacking BIN1, and more generally that BAR domain proteins could be negative regulators of dynamins, as shown before for dynamin 1 and endophilin. ${ }^{40}$ BIN1 and DNM2 form a complex and the absence of BIN1 in Binl mck-l- mice $^{\text {m }}$ could result in an increase in DNM2 protein levels. ${ }^{12}$ In this line, DNM2 reduction via antisense oligonucleotides may represent a first translational approach to treat CNM related to BINI mutations. The existence of at least one founder BINI mutation in the Roma/Gypsy ethnic minority should foster further pre-clinical development. Noteworthy, as we previously showed that DNM2 downregulation rescues mouse models for myotubular myopathy (MTM1-CNM) and dominant DNM2-CNM, it becomes clear that DNM2 antisense oligonucleotides could represent a common therapy to treat these different CNM forms. ${ }^{22}$ Noteworthy a $50 \%$ decrease in DNM2 in mice, either 
from embryogenesis in the Dnm $2^{+/-}$knockout or upon postnatal ASO treatment, ${ }^{18,24,25,27}$ does not lead to detectable toxic effects. DNM2 downregulation is on clinical trial for MTM1 and DNM2CNM patients of more than 16 years old (NCT04033159) by Dynacure, and our present data on this novel BIN1-CNM model supports the inclusion of BIN1-CNM patients in such trial.

BIN1 is also strongly associated with other diseases: ${ }^{41}$ BIN1 mis-splicing was proposed to be a main cause of the skeletal muscle phenotypes of myotonic dystrophy, ${ }^{37}$ decreased BIN1 plasma levels correlate with arrhythmia and with heart failure, ${ }^{42}$ BIN1 was found downregulated in several cancers including breast and colon cancers, ${ }^{43}$ and BIN1 is the second most important risk factor after APOE for late-onset Alzheimer disease. ${ }^{44}$ The therapeutic proof-of-concept validated here for centronuclear myopathy may trigger additional avenues of research for these and other diseases.

\section{Materials and Methods}

\section{Animals.}

Animal care and experimentation was in accordance with French and European legislation and approved by institutional ethics committee (project numbers 2016031110589922 and 2016052510176016). Mice were placed in ventilated cages with free access to food and water in temperature-controlled rooms with $12 \mathrm{~h}$ day light/dark cycles. Bin1 $1^{\text {mck-- }}$ mouse line was established by crossing mice floxed for exon $20\left(\text { Binl } 1^{f l f l}\right)^{18}$ with Bin $1^{f l /+}$ mice expressing the Cre recombinase under the control of the muscle creatine kinase promoter (MCK-Cre; The Jackson laboratory, USA). ${ }^{45}$ Both lines were on a pure C57BL/6J background. Tail biopsies were used for genotyping testing for the floxed allele with 5'AGTGACCTAGGACTGTACCCAGAG3' and 5'ACAGGtAGGTGAAAGAGACTTGG3' and the Cre recombinase gene with 5'GAACCTGATGGACATGTTCAGG3' and 5'AGTGCGTTCGAACGCTAGAGCCTGT3'. Male littermates were analyzed in this study.

\section{Antisense oligonucleotides treatment.}

Antisense oligonucleotides (ASO) used in this study (Ionis Pharmaceuticals, Carlsbad, USA) have phosphorothioate backbone and constrained ethyl (cET) modifications on the wings with a 3-10-3 gapmer design. They were designed to target all the murine isoforms of Dnm2 and were previously validated. ${ }^{23,24}$ Binl $^{f l f l}$ and Binl $1^{\text {mck-/ }}$ male mice were treated weekly from 3 weeks to 8 weeks of 
age with intraperitoneal injections of $25 \mathrm{mg} / \mathrm{kg}$ body weight of ASO diluted in sterile PBS or sterile PBS only. Mice were randomly allocated in the ASO and PBS groups at weaning (3 weeks old). Mice were killed 3 days after the last injection for analysis.

\section{RNA extraction and RT-qPCR.}

RNA was extracted from TA of 8 weeks old mice using TRI Reagent (Molecular Research Center, Cincinnati, USA) and cDNA synthesis performed with SuperscriptTM IV Transcriptase (ThermoFischer Scientific, Whaltham, USA). For quantitative PCR, cDNAs were amplified with SYBR Green Master Mix I (Roche Diagnostics, Basel, Switzerland) using 0.1 $\mu \mathrm{M}$ of forward and reverse primers in a Lightcycler® 480 (Roche Diagnostics, Basel, Switzerland). Primers specificity was validated by melting curve and sequencing of amplicons. Several primers were used in previous studies and are summarized in table S1. ${ }^{28,46-48}$ RT-qPCR was performed using technical triplicates and relative mRNA level was calculated with Rpl27 as a housekeeping gene. The data displayed in the figures are the average of the triplicates and the result of a single experiment.

\section{Protein expression studies.}

TA from 8 weeks old mice were lysed in radioimmunoprecipitation assay (RIPA) buffer supplemented with $1 \mathrm{mM}$ PMSF and complete mini-EDTA-free protease inhibitor cocktail (Roche Diagnostics, Basel, Switzerland). Protein concentrations were determined using DC ${ }^{\mathrm{TM}}$ Protein Assay Kit (BioRad, Hercules, USA). Samples were denaturated 5 minutes at $95{ }^{\circ} \mathrm{C}$ with $5 \mathrm{X}$ Lane Reducing Buffer (ThermoFischer Scientific, Whaltham, USA) and loaded on 10\% SDS-PAGE gel. Proteins were transferred to a nitrocellulose or PVDF membrane using Transblot ${ }^{\circledR}$ TurboTM RTA Transfer Kit (BioRad, Hercules, USA). Loading was controlled by Ponceau S staining before to membrane blocking. Membranes were blocked $1 \mathrm{~h}$ with 5\% non-fat dry milk in $0.1 \%$ Tween 20 prior to incubations with primary and secondary antibodies. The primary and secondary antibodies used were: pan-BIN1 (Rabbit, 1:1000, R3623; homemade anti-BIN1 SH3 domain), pan-DNM2 (Rabbit, 1:700, R2865; homemade anti-DNM2 PRD), ${ }^{49}$ Prohibitin (Rabbit, 1:500, ab28172), P62 (Mouse, 1:1000, H00008878-M01), LC3 (Rabbit, 1:1000, NB100-2220), peroxidase-coupled goat anti-rabbit (Goat, 1/10000, 112-036-04) and peroxidase-coupled goat anti-mouse (Goat, 1/10000, 115-036-068). The data displayed in the figures are the result of a single experiment. 


\section{Mice phenotyping.}

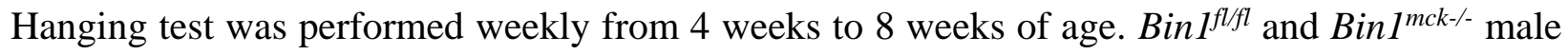
mice were suspended on a cage lid for up to 60 seconds and the time to fall was recorded. The test was replicated 3 times with a time interval of 5 minutes to rest and the average hanging time was calculated. At 6 weeks of age, the mice performed a rotarod test with increasing speed (4-40 rpm) for a maximum of 5 minutes on a rotarod apparatus (Bioseb, Vitrolles, France). The mice were trained on day 1 and tested on the following 4 days when the latency time to fail was recorded three times with 5 minutes resting intervals and the average latency was calculated for each experimental day. At 7 weeks of age, the mice performed the string test. Mice were suspended on a wire by their forelimbs and the time to reach the wire with their hindlimbs was recorded with a maximum time of 20 seconds and any fall was recorded as 20 seconds. The experiment was replicated 3 times with a resting time of 5 minutes. At 4 months of age, exhaustion test was performed using treadmill apparatus (Bioseb). The experiment was initialized with 5 degrees of inclination and $25 \mathrm{~cm} / \mathrm{s}$ of speed that increased up to 15 degrees of inclination and $41 \mathrm{~cm} / \mathrm{s}$ over 150 minutes. Stimulation to keep the mouse on track was performed with an individual grip per lane delivering mild electric shocks (less than $0.2 \mathrm{~mA}$ ). Test was stopped when mice receive more than 100 shocks/5 minutes or they stayed 20 consecutive seconds next to the electrodes, and maximal distance covered and latency time were recorded. Habituation for this test was done the day before the experiment for 10 minutes with an inclination of 5 degrees and speed of $25 \mathrm{~cm} / \mathrm{s}$.

\section{In situ muscle force.}

The force production of the TA was assessed with the Complete1300A Mouse Test System (Aurora Scientific, Aurora, Canada). 8 weeks, 4 months and 12 months old Bin $1^{f l f l}$ and Binl ${ }^{\text {mck-/- }}$ male mice were anesthetized through a triple shot cocktail by intraperitoneal injection of 1) domitor/fentanyl mix $(2 / 0.28 \mathrm{mg} / \mathrm{kg}), 2)$ diazepam $(8 \mathrm{mg} / \mathrm{kg})$ and 3$)$ domitor $(0.28 \mathrm{mg} / \mathrm{kg})$. The distal tendon was excised and attached to the muscle transducer while knees and feet were fixed. The sciatic nerve was stimulated by electrical pulses with increasing frequency from 1 to $125 \mathrm{~Hz}$ in order to measure maximal force. The specific force was determined by dividing the maximal force with the muscle weight (mg).

\section{Histology, immunofluorescence and electron microscopy.}


TA, gastrocnemius, FDB andheart were dissected and frozen in liquid nitrogen-cooled isopentane and $8 \mu \mathrm{m}$ cryosections were stained with hematoxylin-eosin (HE), succinate dehydrogenase (SDH), nicotinamide adenine dinucleotide dehydrogenase (NADH) or modified Gomori.

Fiber size distribution, circularity and nuclei counting were determined on $8 \mu \mathrm{m}$ cryosections from 8 weeks TA cryosections stained with Hoechst (Sigma-Aldrich, St Louis, USA) and Wheat Germ Agglutinin Alexa Fluor ${ }^{\mathrm{TM}} 555$ conjugate (ThermoFischer Scientific, Whaltham, USA) to stain nuclei and plasma membrane, respectively. Images were recorded using the Nanozoomer 2HT slide scanner (Hamamatsu, Japan) and the fiber size and nuclei counting analysis was performed using a homemade ImageJ plugin as described.$^{50}$ For FDB from 8 weeks old mice and TA from 4 months and 12 months old mice, fiber segmentation was performed using HE images and Cellpose software for segmentation algorithm. ${ }^{51}$ Fiber MinFere diameter and nuclei counting were calculated or counted using ImageJ. For fiber circularity distribution, the fibers were classified with a value from 0 to 1 where 0 corresponds to a line and 1 to a circle, and one transversal section of the whole muscle was quantified. For immunofluorescence, $8 \mu \mathrm{m}$ TA cryosections were fixed with paraformaldehyde $4 \%$, blocked with fetal calf serum and sequentially incubated with antiprohibitin (Rabbit, 1:500, ab28172), anti-LC3 (Rabbit, 1:1000, NB100-2220), anti-desmin (Rabbit, 1:200, ab15200) or anti-TOMM20 (Rabbit, 1:100, ab78547), and Alexa-Fluor 594-coupled goat anti-Rabbit (Goat, 1/250, A11012) and or Alexa-Fluor 488-coupled goat anti-Rabbit (Goat, 1/250, A11008) and Hoechst (Sigma-Aldrich, St Louis, USA). Confocal microscopy images were recorded on a SP8 confocal microscope (Leica, Wetzlar, Germany) and image analysis and counting performed with ImageJ.

For electron microscopy, small pieces of TA were fixed in $2.5 \%$ glutaraldehyde, $2.5 \%$ paraformaldehyde, $50 \mathrm{mM} \mathrm{Ca}^{2+}$ in cacodylate buffer (0.1M, pH 7.4). For inclusion, samples were washed in cacodylate buffer for 30 minutes, postfixed in $1 \%$ osmium tetroxide in $0.1 \mathrm{M}$ cacodylate for $1 \mathrm{~h}$ at $4{ }^{\circ} \mathrm{C}$. Samples were dehydrated through graded alcohol (50\%, 70\%, 90\% and 100\%) and propylene oxide for 30 minutes each and embedded in Epon 812. Seventy nm ultrathin sections were cut on a Leica Ultracut microtome (Leica, Wetzlar, Germany), contrasted with uranyl acetate and lead citrate, and examined at 70kv with a Morgagni 268D electron microscope (FEI, Electron Optics, Eindhoven, Netherlands). Images were captured digitally by a Mega View III Camera (Soft Imaging System, Münster, Germany). 


\section{Electrophysiology, intracellular $\mathrm{Ca}^{2+}$ measurements.}

Single fibers were isolated from the flexor digitorum brevis (FDB) and interosseus muscles of 3 $B i n 1^{f l f l}$ and 3 Bin $1^{\text {mck-/ }}$ mice using previously described procedures. ${ }^{52}$ In brief, 8 weeks old mice were anaesthetized by isoflurane inhalation and killed by cervical dislocation. Muscles were removed and incubated for 45 minutes at $37^{\circ} \mathrm{C}$ in Tyrode solution supplemented with type 1 collagenase (Sigma-Aldrich, St Louis, USA). Single fibers were then separated by gentle mechanical trituration within a culture $\mu$-dish (Ibidi, Planegg / Martinsried, Germany).

For electrophysiology measurements fibers from the interosseus muscles were used (5-6 fibers per mouse). The bottom of a $\mu$-dish was first covered with a thin layer of silicone grease, and muscle trituration was performed in culture medium containing 10\% fetal bovine serum (MI199; Eurobio, France). Isolated fibers were painted with silicone so that only a short portion of one fiber end remained out of the silicone, in contact with the bathing solution. The culture medium was then replaced by the experimental extracellular solution containing $140 \mathrm{mM}$ TEA-methane-sulfonate, $2.5 \mathrm{mM} \mathrm{CaCl}_{2}, 2 \mathrm{mM} \mathrm{MgCl}, 1 \mathrm{mM}$ 4-aminopyridine, $10 \mathrm{mM}$ HEPES and $0.002 \mathrm{mM}$ tetrodotoxin ( $\mathrm{pH}$ 7.2). Voltage-clamp was achieved with a glass micropipette connected to a RK-400 patchclamp amplifier (Bio-Logic, Claix, France) in whole-cell configuration, in combination with an analog-digital converter (Digidata 1440A, Axon Instruments, Foster City, CA) controlled by pClamp 9 software (Axon Instruments). The micropipette was filled with a solution containing $120 \mathrm{mM}$ K-glutamate, $5 \mathrm{mM} \mathrm{Na} 2$-ATP, $5 \mathrm{mM} \mathrm{Na}$-phosphocreatine, $5.5 \mathrm{mM} \mathrm{MgCl} 2,5 \mathrm{mM}$ glucose, $15 \mathrm{mM}$ EGTA, $6 \mathrm{mM} \mathrm{CaCl} 2,0.1 \mathrm{mM}$ rhod-2 and $5 \mathrm{mM}$ HEPES (pH 7.2). The pipette tip was inserted into the silicone-insulated part of the fiber. It was gently crushed against the bottom of the $\mu$-dish to ease dialysis and reduce series resistance. The fiber cytosol was dialyzed for 30 min to allow for intracellular equilibration of the solution before starting measurements.

Cav1.1 $\mathrm{Ca}^{2+}$ current and rhod-2 (Thermo Fisher Scientific, Illkirch, France) intracellular $\mathrm{Ca}^{2+}$ transients were simultaneously measured in response to 0.5 s-long depolarizing steps from a holding voltage of $-80 \mathrm{mV}$. For Cav1.1 current analysis, the linear leak component of the current during the test pulses was removed by subtracting the adequately scaled current value measured during a $20 \mathrm{mV}$ hyperpolarizing step. A residual leak component (referred to as slope) was found to be larger in fibers from Bin $1^{f l f l}$ mice than in fibers from Bin $1^{m c k-/}$ mice. Thus, for each fiber, the voltage-dependence of peak $\mathrm{Ca}^{2+}$ current values (normalized to fiber capacitance) was fitted with 
the following equation: $\mathrm{I}(\mathrm{V})=\mathrm{G}_{\max }\left(\mathrm{V}-\mathrm{V}_{\text {rev }}\right) /\left(1+\left[\exp \left(\mathrm{V}_{0.5}-\mathrm{V}\right) / \mathrm{k}\right]\right)+\operatorname{slope}(\mathrm{V}+80)$, with $\mathrm{I}(\mathrm{V})$ the peak current density at the command voltage $\mathrm{V}, \mathrm{G}_{\max }$ the maximum conductance, $\mathrm{V}_{\text {rev }}$ the apparent reversal potential, $\mathrm{V}_{0.5}$ the half-activation potential, $\mathrm{k}$ the steepness factor, and slope the conductance of the residual linear component.

Fluorescence imaging was conducted with a Zeiss LSM-800 system equipped with a $63 \times$ oil immersion objective (numerical aperture 1.4). For detection of rhod-2 fluorescence, excitation was from a $561 \mathrm{~nm}$ diode laser and fluorescence was collected above $570 \mathrm{~nm}$. Fluorescence changes were imaged using the line-scan mode $(\mathrm{x}, \mathrm{t})$ of the system with a scanning frequency of $1.02 \mathrm{~ms}$ per line and expressed as $\mathrm{F} / \mathrm{F}_{0}$ where $\mathrm{F}_{0}$ is the baseline fluorescence. Quantification of the $\mathrm{Ca}^{2+}$ release flux underlying the rhod- $2 \mathrm{Ca} 2+$ transients was performed as previously described. ${ }^{52,53} \mathrm{In}$ each fiber, the voltage-dependence of the peak rate of $\mathrm{Ca}^{2+}$ release was fitted with a Boltzmann function.

For imaging the T-tubule network, flexor digitorum brevis muscle fibers were incubated for 30 minutes in the presence of $10 \mu \mathrm{M}$ di-8-anepps (Thermo Fisher Scientific, Illkirch, France). Di-8anepps was excited with a $488 \mathrm{~nm}$ diode laser and fluorescence was collected above $510 \mathrm{~nm}$. The T-tubule density index (9-13 fibers per mouse) was estimated as described previously. ${ }^{54}$

\section{Statistical analysis.}

All experiments were performed and analyzed in a blinded manner and the investigators were unaware of the genotype of the mice. The normal distribution of the data was assessed using the Shapiro-Wilk test and presented as mean \pm standard error of the mean (SEM) with exception of data compared with Kruskal-Wallis test where the data is presented as median \pm interquartile range. For normally distributed data the significance of changes was examined by two-tailed Student's t-test (with or without Welch's correction if variance was different or not) for comparison of 2 groups or by one-way ANOVA followed by Tukey's post hoc test for comparison of more than 2 groups. In case of not-normally distributed data, Mann-Whitney test was used to compare 2 groups and Kruskal-Wallis followed by Dunn's multiple comparison test to compare more than 2 groups. The significant difference of birth ratio was assessed by chi-square test. Significant differences are illustrated as $* P<0.05, * * P<0.01$, $* * * P<0.001$ and $* * * * P<0.0001$. 


\section{Data availability.}

The authors confirm that the data supporting the findings of this study are available within the article and its supplementary material.

\section{Acknowledgements}

We thank IGBMC and ICS platforms for animal care, histology, photonic and electron imaging, Shuling Guo and Brett Monia for providing the Dnm2 antisense oligonucleotide, Quentin Giraud for his help with mice. and Doulaye Dembélé for the statistical analysis assistance. The creation of the Bin ${ }^{f l f l}$ mouse was done with Phenomin-ICS, Illkirch, France.

This study was supported by institute funding from Institut National de la Santé et de la Recherche Médicale, Centre National de la Recherche Scientifique, Université de Strasbourg and by grants from the Agence Nationale de la Recherche ANR-10-LABX-0030-INRT, a French State fund managed by the Agence Nationale de la Recherche under the frame program Investissements d'Avenir ANR-10-IDEX-0002-02, Réseau National des Génopoles (RNG), the European Union's Horizon 2020 research and innovation program under the Marie Skłodowska-Curie grant agreement (675392), Muscular Dystrophy Association (576154), Fondation pour la Recherche Médicale (201903007992), and AFM-Téléthon (21267, 22734, MyoNeurALP \# 5.3.4.4). R.G.O. had a CIFRE fellowship obtained with Dynacure, and R.S.R. a fellowship from Fondation pour la Recherche Médicale (PLP20170939073).

\section{Authors' contributions}

All experiments were done in IGBMC. J.L. designed the study; B.S.C., V.J. and J.L. supervised research; V.N., R.S.R., F.J-F., A.M., R.G.O., N.M., V.M.L., D.R., C.K. performed research; V.N., R.S.R., F.J-F., R.G.O., M.G., N.M., D.R, V.J. analyzed data; R.S.R. and J.L. wrote the manuscript.

\section{Competing interests}

J. Laporte and B. S. Cowling are co-founders of Dynacure, B. S. Cowling is employed by Dynacure and R Gomez Oca has a CIFRE fellowship with Dynacure.

Keywords: myopathy, antisense oligonucleotides, membrane curvature, dynamin, amphiphysin, therapy 


\section{References}

1. Jungbluth, H, Wallgren-Pettersson, C, and Laporte, J (2008). Centronuclear (myotubular) myopathy. Orphanet J Rare Dis 3: 26.

2. Gonorazky, HD, Bonnemann, CG, and Dowling, JJ (2018). The genetics of congenital myopathies. Handb Clin Neurol 148: 549-564.

3. Romero, NB (2010). Centronuclear myopathies: a widening concept. Neuromuscul Disord 20: $223-228$.

4. Lawlor, MW, Beggs, AH, Buj-Bello, A, Childers, MK, Dowling, JJ, James, ES, et al. (2016). Skeletal Muscle Pathology in X-Linked Myotubular Myopathy: Review With CrossSpecies Comparisons. J Neuropathol Exp Neurol 75: 102-110.

5. Schartner, V, Laporte, J, and Bohm, J (2019). Abnormal Excitation-Contraction Coupling and Calcium Homeostasis in Myopathies and Cardiomyopathies. J Neuromuscul Dis 6: 289-305.

6. Lornage, X, Schartner, V, Balbueno, I, Biancalana, V, Willis, T, Echaniz-Laguna, A, et al. (2019). Clinical, histological, and genetic characterization of PYROXD1-related myopathy. Acta Neuropathol Commun 7: 138.

7. Pelin, K, and Wallgren-Pettersson, C (2019). Update on the Genetics of Congenital Myopathies. Semin Pediatr Neurol 29: 12-22.

8. Toussaint, A, Cowling, BS, Hnia, K, Mohr, M, Oldfors, A, Schwab, Y, et al. (2011). Defects in amphiphysin 2 (BIN1) and triads in several forms of centronuclear myopathies. Acta Neuropathol 121: 253-266.

9. Hohendahl, A, Roux, A, and Galli, V (2016). Structural insights into the centronuclear myopathy-associated functions of BIN1 and dynamin 2. J Struct Biol 196: 37-47.

10. Lee, E, Marcucci, M, Daniell, L, Pypaert, M, Weisz, OA, Ochoa, GC, et al. (2002). Amphiphysin 2 (Bin1) and T-tubule biogenesis in muscle. Science 297: 1193-1196.

11. Bohm, J, Biancalana, V, Malfatti, E, Dondaine, N, Koch, C, Vasli, N, et al. (2014). Adultonset autosomal dominant centronuclear myopathy due to BIN1 mutations. Brain 137: 3160-3170.

12. Nicot, AS, Toussaint, A, Tosch, V, Kretz, C, Wallgren-Pettersson, C, Iwarsson, E, et al. (2007). Mutations in amphiphysin 2 (BIN1) disrupt interaction with dynamin 2 and cause autosomal recessive centronuclear myopathy. Nat Genet 39: 1134-1139.

13. Cabrera-Serrano, M, Mavillard, F, Biancalana, V, Rivas, E, Morar, B, Hernandez-Lain, A, et al. (2018). A Roma founder BIN1 mutation causes a novel phenotype of centronuclear myopathy with rigid spine. Neurology. 
14. Gowrisankaran, S, Wang, Z, Morgan, DG, Milosevic, I, and Mim, C (2020). Cells Control BIN1-Mediated Membrane Tubulation by Altering the Membrane Charge. J Mol Biol 432: 12351250 .

15. Razzaq, A, Robinson, IM, McMahon, HT, Skepper, JN, Su, Y, Zelhof, AC, et al. (2001). Amphiphysin is necessary for organization of the excitation-contraction coupling machinery of muscles, but not for synaptic vesicle endocytosis in Drosophila. Genes Dev 15: 2967-2979.

16. Smith, LL, Gupta, VA, and Beggs, AH (2014). Bridging integrator 1 (Bin1) deficiency in zebrafish results in centronuclear myopathy. Hum Mol Genet 23: 3566-3578.

17. Bohm, J, Vasli, N, Maurer, M, Cowling, B, Shelton, GD, Kress, W, et al. (2013). Altered Splicing of the BIN1 Muscle-Specific Exon in Humans and Dogs with Highly Progressive Centronuclear Myopathy. PLoS Genet 9: e1003430.

18. Cowling, BS, Prokic, I, Tasfaout, H, Rabai, A, Humbert, F, Rinaldi, B, et al. (2017). Amphiphysin (BIN1) negatively regulates dynamin 2 for normal muscle maturation. J Clin Invest 127: 4477-4487.

19. Muller, AJ, Baker, JF, DuHadaway, JB, Ge, K, Farmer, G, Donover, PS, et al. (2003). Targeted disruption of the murine Bin1/Amphiphysin II gene does not disable endocytosis but results in embryonic cardiomyopathy with aberrant myofibril formation. Mol Cell Biol 23: 42954306.

20. Prokic, I, Cowling, BS, Kutchukian, C, Kretz, C, Tasfaout, H, Gache, V, et al. (2020). Differential physiological role of BIN1 isoforms in skeletal muscle development, function and regeneration. Dis Model Mech.

21. Tjondrokoesoemo, A, Park, KH, Ferrante, C, Komazaki, S, Lesniak, S, Brotto, M, et al. (2011). Disrupted membrane structure and intracellular $\mathrm{Ca}(2)(+)$ signaling in adult skeletal muscle with acute knockdown of Bin1. PLoS One 6: e25740.

22. Tasfaout, H, Cowling, BS, and Laporte, J (2018). Centronuclear myopathies under attack: A plethora of therapeutic targets. J Neuromuscul Dis 5: 387-406.

23. Buono, S, Ross, JA, Tasfaout, H, Levy, Y, Kretz, C, Tayefeh, L, et al. (2018). Reducing dynamin 2 (DNM2) rescues DNM2-related dominant centronuclear myopathy. Proc Natl Acad Sci U S A.

24. Tasfaout, H, Buono, S, Guo, S, Kretz, C, Messaddeq, N, Booten, S, et al. (2017). Antisense oligonucleotide-mediated Dnm2 knockdown prevents and reverts myotubular myopathy in mice. Nat Commun 8: 15661.

25. Buono, S, Ross, JA, Tasfaout, H, Levy, Y, Kretz, C, Tayefeh, L, et al. (2018). Reducing dynamin 2 (DNM2) rescues DNM2-related dominant centronuclear myopathy. Proc Natl Acad Sci U S A 115: 11066-11071. 
26. Cowling, BS, Chevremont, T, Prokic, I, Kretz, C, Ferry, A, Coirault, C, et al. (2014). Reducing dynamin 2 expression rescues X-linked centronuclear myopathy. J Clin Invest 124: $1350-1363$.

27. Massana Munoz, X, Kretz, C, Silva-Rojas, R, Ochala, J, Menuet, A, Romero, NB, et al. (2020). Physiological impact and disease reversion for the severe form of centronuclear myopathy linked to dynamin. JCI Insight 5.

28. Durieux, AC, Vignaud, A, Prudhon, B, Viou, MT, Beuvin, M, Vassilopoulos, S, et al. (2010). A centronuclear myopathy-dynamin 2 mutation impairs skeletal muscle structure and function in mice. Hum Mol Genet 19: 4820-4836.

29. Hnia, K, Tronchere, H, Tomczak, KK, Amoasii, L, Schultz, P, Beggs, AH, et al. (2011). Myotubularin controls desmin intermediate filament architecture and mitochondrial dynamics in human and mouse skeletal muscle. J Clin Invest 121: 70-85.

30. Tasfaout, H, Lionello, VM, Kretz, C, Koebel, P, Messaddeq, N, Bitz, D, et al. (2018). Single Intramuscular Injection of AAV-shRNA Reduces DNM2 and Prevents Myotubular Myopathy in Mice. Mol Ther 26: 1082-1092.

31. Prokic, I, Cowling, BS, Kutchukian, C, Kretz, C, Tasfaout, H, Gache, V, et al. (2020). Differential physiological roles for BIN1 isoforms in skeletal muscle development, function and regeneration. Dis Model Mech 13.

32. Pierson, CR, Agrawal, PB, Blasko, J, and Beggs, AH (2007). Myofiber size correlates with MTM1 mutation type and outcome in X-linked myotubular myopathy. Neuromuscul Disord 17: 562-568.

33. Roman, W, Martins, JP, Carvalho, FA, Voituriez, R, Abella, JVG, Santos, NC, et al. (2017). Myofibril contraction and crosslinking drive nuclear movement to the periphery of skeletal muscle. Nat Cell Biol 19: 1189-1201.

34. Falcone, S, Roman, W, Hnia, K, Gache, V, Didier, N, Laine, J, et al. (2014). N-WASP is required for Amphiphysin-2/BIN1-dependent nuclear positioning and triad organization in skeletal muscle and is involved in the pathophysiology of centronuclear myopathy. EMBO Mol Med 6: $1455-1475$.

35. D'Alessandro, M, Hnia, K, Gache, V, Koch, C, Gavriilidis, C, Rodriguez, D, et al. (2015). Amphiphysin 2 Orchestrates Nucleus Positioning and Shape by Linking the Nuclear Envelope to the Actin and Microtubule Cytoskeleton. Dev Cell 35: 186-198.

36. Takekura, H, Flucher, BE, and Franzini-Armstrong, C (2001). Sequential docking, molecular differentiation, and positioning of T-Tubule/SR junctions in developing mouse skeletal muscle. Dev Biol 239: 204-214.

37. Fugier, C, Klein, AF, Hammer, C, Vassilopoulos, S, Ivarsson, Y, Toussaint, A, et al. (2011). Misregulated alternative splicing of BIN1 is associated with $\mathrm{T}$ tubule alterations and muscle weakness in myotonic dystrophy. Nat Med 17: 720-725. 
38. Hong, T, Yang, H, Zhang, SS, Cho, HC, Kalashnikova, M, Sun, B, et al. (2014). Cardiac BIN1 folds T-tubule membrane, controlling ion flux and limiting arrhythmia. Nat Med 20: 624632.

39. Caldwell, JL, Smith, CE, Taylor, RF, Kitmitto, A, Eisner, DA, Dibb, KM, et al. (2014). Dependence of cardiac transverse tubules on the BAR domain protein amphiphysin II (BIN-1). Circ Res 115: 986-996.

40. Hohendahl, A, Talledge, N, Galli, V, Shen, PS, Humbert, F, De Camilli, P, et al. (2017). Structural inhibition of dynamin-mediated membrane fission by endophilin. Elife 6 .

41. Prokic, I, Cowling, BS, and Laporte, J (2014). Amphiphysin 2 (BIN1) in physiology and diseases. J Mol Med (Berl) 92: 453-463.

42. Hong, TT, Cogswell, R, James, CA, Kang, G, Pullinger, CR, Malloy, MJ, et al. (2012). Plasma BIN1 correlates with heart failure and predicts arrhythmia in patients with arrhythmogenic right ventricular cardiomyopathy. Heart Rhythm 9: 961-967.

43. Prendergast G.C, MAJ, Ramalingam A and Chang M.Y (2009). Bar the door : cancer suppression by amphiphysin-like genes. Biochemica et Biophysica Acta 1795: 25-36.

44. Seshadri, S, Fitzpatrick, AL, Ikram, MA, DeStefano, AL, Gudnason, V, Boada, M, et al. (2010). Genome-wide analysis of genetic loci associated with Alzheimer disease. JAMA 303: $1832-1840$.

45. Bruning, JC, Michael, MD, Winnay, JN, Hayashi, T, Horsch, D, Accili, D, et al. (1998). A muscle-specific insulin receptor knockout exhibits features of the metabolic syndrome of NIDDM without altering glucose tolerance. Mol Cell 2: 559-569.

46. Honda, M, Hidaka, K, Fukada, SI, Sugawa, R, Shirai, M, Ikawa, M, et al. (2017). Vestigiallike 2 contributes to normal muscle fiber type distribution in mice. Sci Rep 7: 7168.

47. Kuno, A, Hosoda, R, Sebori, R, Hayashi, T, Sakuragi, H, Tanabe, M, et al. (2018). Resveratrol Ameliorates Mitophagy Disturbance and Improves Cardiac Pathophysiology of Dystrophin-deficient mdx Mice. Sci Rep 8: 15555.

48. Thomas, KC, Zheng, XF, Garces Suarez, F, Raftery, JM, Quinlan, KG, Yang, N, et al. (2014). Evidence based selection of commonly used RT-qPCR reference genes for the analysis of mouse skeletal muscle. PLoS One 9: e88653.

49. Cowling, BS, Toussaint, A, Amoasii, L, Koebel, P, Ferry, A, Davignon, L, et al. (2011). Increased expression of wild-type or a centronuclear myopathy mutant of dynamin 2 in skeletal muscle of adult mice leads to structural defects and muscle weakness. Am J Pathol 178: 22242235.

50. Silva-Rojas, R, Treves, S, Jacobs, H, Kessler, P, Messaddeq, N, Laporte, J, et al. (2019). STIM1 over-activation generates a multi-systemic phenotype affecting the skeletal muscle, spleen, eye, skin, bones and immune system in mice. Hum Mol Genet 28: 1579-1593. 
51. Stringer, C, Wang, T, Michaelos, M, and Pachitariu, M (2021). Cellpose: a generalist algorithm for cellular segmentation. Nat Methods 18: 100-106.

52. Lefebvre, R, Pouvreau, S, Collet, C, Allard, B, and Jacquemond, V (2014). Whole-cell voltage clamp on skeletal muscle fibers with the silicone-clamp technique. Methods Mol Biol 1183: 159-170.

53. Kutchukian, C, Lo Scrudato, M, Tourneur, Y, Poulard, K, Vignaud, A, Berthier, C, et al. (2016). Phosphatidylinositol 3-kinase inhibition restores $\mathrm{Ca} 2+$ release defects and prolongs survival in myotubularin-deficient mice. Proc Natl Acad Sci U S A 113: 14432-14437.

54. Kutchukian, C, Szentesi, P, Allard, B, Trochet, D, Beuvin, M, Berthier, C, et al. (2017). Impaired excitation-contraction coupling in muscle fibres from the dynamin2(R465W) mouse model of centronuclear myopathy. J Physiol 595: 7369-7382.

\section{Figure Legends}

Figure 1. Muscle-specific BinI ${ }^{\text {mck-- }}$ mice are viable with impaired TA muscle force. (A) Homozygous Binl $1^{m c k-/}$ mice were generated by crossing Bin $1^{f l f l}$ with heterozygous floxed Binl mice expressing the Cre recombinase under the control of the muscle creatine kinase promoter (MCK-Cre). The represented situation refers to skeletal muscle. (B) Genotype proportion obtained 10 days after birth; expected ratio is 50/50. (C) Bin $1^{f l f f l}$ and Binl ${ }^{m c k-l}$ mice at 8 weeks of age. (D) Binl mRNA pan-isoform relative levels in TA from Bin $1^{f l f l}$ and Binl ${ }^{m c k-l}$ mice at 8 weeks of age ( $\mathrm{n}=4$; Student t-test with Welch's correction). (E) Western blot with TA muscle protein extracts probed with anti-BIN1 pan-isoform antibody. BIN1 is not detected in Binl $1^{\text {mck-l }}$ muscle. (F) Body weight evolution of Bin $1^{f l f l}$ and Binl ${ }^{\text {mck-l }}$ mice ( $\mathrm{n}=8-9$; two-way ANOVA and Bonferroni post hoc test). (G) Specific muscle force produced by TA of Bin $1^{f l f l}$ and Bin $1^{\text {mck- }- \text { at }} 8$ weeks of age (n=89; Student's t test). Binl ${ }^{\text {mck-l }}$ mice produce $41 \%$ less specific force than Bin $f^{f l f l}$ controls. $(\mathrm{H})$ Specific force produced by Bin $1^{f l f l}$ and Bin $1^{m c k-/}$ TA when stimulated at different frequencies (n=8-9; two-way ANOVA with Bonferroni's post hoc test). $* * * P<0.0001$; $* * * P<0.001$; $* * P<0.01$.

Figure 2. Bin1 ${ }^{\text {mck-l- }}$ mice develop most of the histopathological hallmarks of CNM in TA. (A) Representative HE and SDH images of TA from Bin $1^{f l f l}$ and Binl ${ }^{m c k-/}$ mice at 8 weeks of age. Binl $^{\text {mck-l- }}$ muscle sections present SDH accumulations in the center of fibers (arrows; $n=3$ ). Scale bar $=50 \mu \mathrm{m}$. (B) MinFeret perimeter distribution of TA fibers $(n=4-5)$. (C) The percentage of large 
fibers with MinFeret diameter higher than $40 \mu \mathrm{m}$ is reduced in Bin1 $1^{\text {mck-/ }}$ compared to Binl flffl controls ( $\mathrm{n}=4-5$; Student's t test). (D) Myofiber circularity distribution in TA; a value of 0

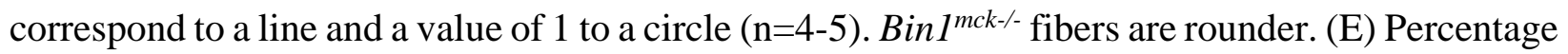
of fibers with internalized nuclei reveals no difference between Bin $1^{\text {mck-l- }}$ and Binl ${ }^{f l f l}$ muscles (n=4-5; Student's t test). $* * * * P<0.0001 ; * * * P<0.001 ; * * P<0.01 ; * P<0.05$.

Figure 3. Bin ${ }^{m c k-/-}$ mice present myofibrils disorganization and mitochondria accumulation in TA. (A) Electron microscopy images from Binl $1^{f l f l}$ and Binl ${ }^{m c k-/}$ at 8 weeks of age reveal overall myofibrils disorganization with higher inter-myofibril spaces (left) while nuclear shape and position remain normal in Binl $1^{\text {mck-/ }}$ mice (right) $(\mathrm{n}=2)$. Scale bar $=1 \mu \mathrm{m}$. (B) Mitochondria accumulations in Binl $1^{\text {mck-/ }}$ muscle observed by electron microscopy (left) and revealed with prohibitin staining (right) $(\mathrm{n}=2)$. Scale bar $=1 \mu \mathrm{m}$ for electron microscopy and $10 \mu \mathrm{m}$ for confocal microscopy. (C) Quantification of prohibitin protein expression ( $\mathrm{n}=3$; Student's t test). (D) Ppargcla mRNA relative levels ( $\mathrm{n}=6$; Student's t test). (E) Regions with mitochondria accumulation (arrow) in Binl $1^{\text {mck- }}$ muscle present autophagosomes (arrowhead; left), and immunofluorescence labelling reveals increased number of autophagic LC3 positive clusters (right) (n=2). (F-G) P62 and lipidated LC3 (II) protein levels (n=4; Student's t test for P62 and Student t-test with Welch's correction for lipidated LC3). $* * P<0.01$.

Figure 4. Deficient voltage-dependent $\mathrm{Ca}^{2+}$ signaling in muscle fibers isolated from BinI ${ }^{m c k-}$ /- mice FDB. (A) Representative confocal images of the T-tubule network in muscle fibers from Binl ${ }^{f l f l}$ and Bin1 $1^{\text {mck-l }}$ mice at 8 weeks of age. Scale bar $=10 \mu \mathrm{m}$. (B) Mean values for the T-tubule network density index in the two groups $(n=3$ mice per genotype, 9-13 fibers analyzed per mice; Student's t test). (C) Examples of Cav1.1 $\mathrm{Ca}^{2+}$ current records from muscle fibers from a Bin1 flffl mouse (left) and from a Binl $1^{\text {mck-/ }}$ mouse (right) in response to $0.5 \mathrm{~s}$-long depolarizing pulses to the range of indicated values (voltage increment between -40 and +50 is $10 \mathrm{mV}$ ). (D) Mean values for the peak $\mathrm{Ca}^{2+}$ current vs voltage in the two groups. The voltage dependence of the peak $\mathrm{Ca}^{2+}$ current in each fiber was fitted as described in Methods ( $n=3$ mice per genotype, 5-6 fibers analyzed per mice; Student's t test). (E) Mean values, from fitting the voltage-dependence of the peak $\mathrm{Ca}^{2+}$ current, for the maximum conductance $\left(\mathrm{G}_{\max }\right)$, reversal voltage $\left(\mathrm{V}_{\text {rev }}\right)$, and for the additional linear conductance (slope). Mean values for $\mathrm{V}_{\text {rev }}$ and for the two other fitted parameters (half-activation voltage and steepness factor) did not statistically differ between the two groups 
( $n=3$ mice per genotype, 5-6 fibers analyzed per mice; Student's t test). (F) Representative lineaveraged rhod-2 $\mathrm{Ca}^{2+}$ transients from a Binl ${ }^{f l f l}$ and from a Binl ${ }^{\text {mck-l- }}$ muscle fiber, in response to the indicated voltage pulse protocol (same as in D). From these records the rate of SR $\mathrm{Ca}^{2+}$ release was calculated (dCaTot/dt, see Methods). (G) Mean values for the peak rate of SR Ca ${ }^{2+}$ release vs voltage in the two groups ( $\mathrm{n}=3$ mice per genotype, 5-6 fibers analyzed per mice; Student's $\mathrm{t}$ test). (H) Mean values for the maximum rate of $\mathrm{SR} \mathrm{Ca}^{2+}$ release obtained by fitting the voltagedependence of peak rate in each fiber with a Boltzmann function. Mean values for the two other fitted parameters (mid-activation voltage and steepness factor) did not statistically differ between the two groups. Data are from the same groups of fibers as in $\mathrm{E}(\mathrm{n}=3$ mice per genotype, 5-6 fibers analyzed per mice; Student's t test). $* * * P<0.001 ; * P<0.05$.

Figure 5. Dnm2 downregulation ameliorates the TA muscle force of Bin $1^{m c k-/}$ mice. (A) DNM2 protein expression in TA at 8 weeks of age $(n=4$; Student t-test with Welch's correction). (B) Dnm2 mRNA levels in TA at 8 weeks of age by RT-qPCR for pan-isoforms $(n=4$; two-way ANOVA with Bonferroni's post hoc test). (C) DNM2 protein expression in TA at 8 weeks ( $\mathrm{n}=4$ 7; two-way ANOVA with Bonferroni's post hoc test). (D) Maximal specific force produced by Binl $1^{f l f l}$ and Bin $1^{\text {mck-/- }}$ TA. Only muscle force produced by PBS-treated Bin ${ }^{\text {mck-/- }}$ muscles show a significant decrease compared to Binl ${ }^{\text {flfl }}$ controls ( $\mathrm{n}=4-6$; Kruskal-Wallis with Dunn's post hoc test). (E) Specific force produced when stimulated at increasing frequencies $(n=4-6$; one-way ANOVA with Tukey's post hoc test for 1, 25 and $50 \mathrm{~Hz}$ frequencies and Kruskal-Wallis with

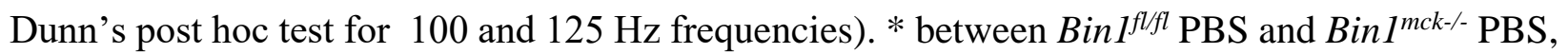
and $\beta$ between Bin1 ${ }^{m c k-/}$ PBS and Bin1 ${ }^{m c k-/}$ ASO. $* * P<0.01 ; * P<0.05 ; \beta \beta P<0.01$. We found no statistical difference between Bin $1^{\text {mck-/ }}$ ASO and Bin ${ }^{f l f l}$ ASO.

Figure 6. Dnm2 downregulation rescues the TA CNM histopathological hallmarks of Bin1 ${ }^{\text {mck- }}$ /. mice. (A-B) Representative HE and SDH images of TA from PBS and ASO-treated Bin $1^{f l f l}$ and Binl ${ }^{m c k-/}$ mice at 8 weeks of age $(\mathrm{n}=4-6)$. Scale bar $=50 \mu \mathrm{m}$. ASO-treated Bin $1^{\text {mck- }}$ mice do not present the central SDH accumulations seen in PBS-treated Bin $1^{\text {mck-l }}$ mice (arrows). (C) MinFeret perimeter distribution of TA fibers from PBS and ASO-treated Bin $1^{f l f l-}$ and Bin1 ${ }^{\text {mck-/- }}$ mice $(\mathrm{n}=4$ 5). (D) Percentage of fibers with MinFeret diameter higher than $40 \mu \mathrm{m}$ are comparable in PBS and ASO-treated Bin1 $1^{f l f l}$ and Bin1 $1^{\text {mck-/- }}$ mice (n=4-7; one-way ANOVA with Tukey's post hoc test). 
(E) Myofiber circularity from ASO-treated Bin $1^{f l f l-}$ and Bin $1^{m c k-/-}$ TA; a value of 0 correspond to a line and a value of 1 to a circle $(\mathrm{n}=4-5)$. $* * P<0.01 ; * P<0.05$. 

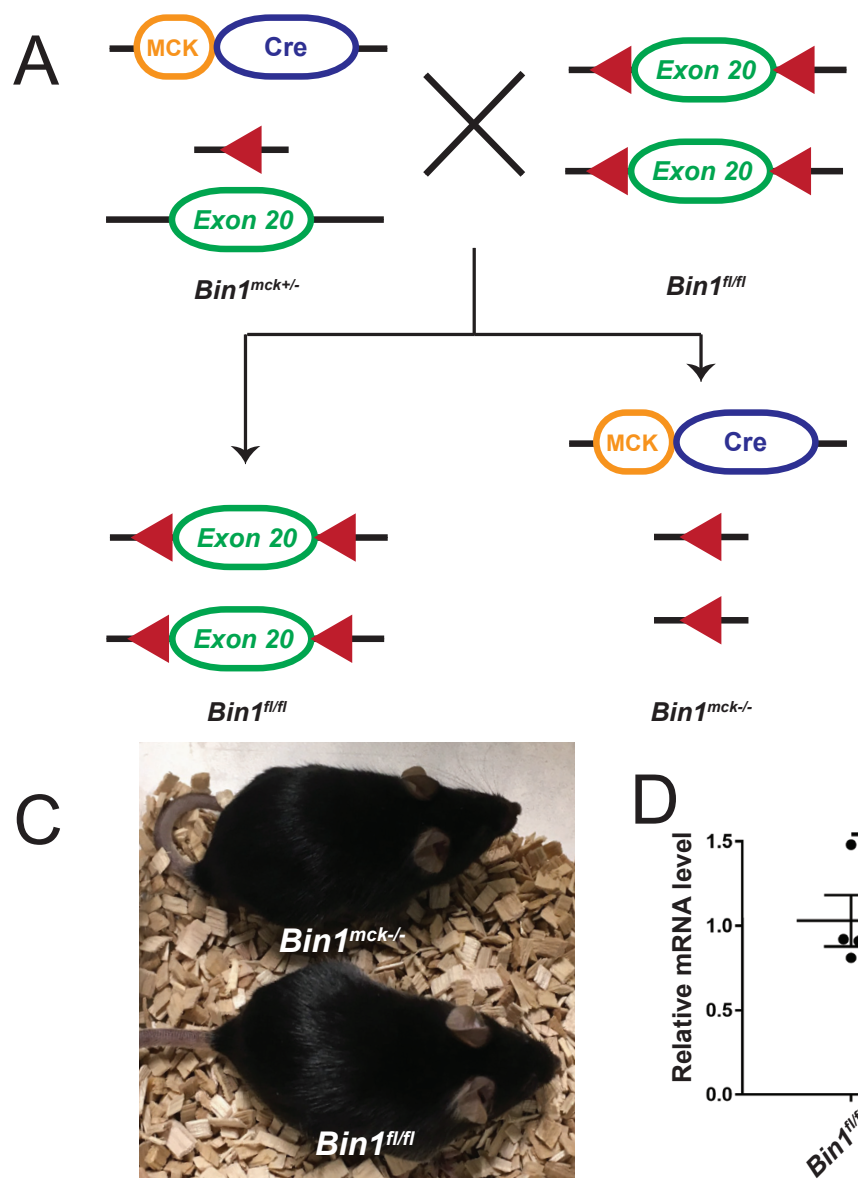

B

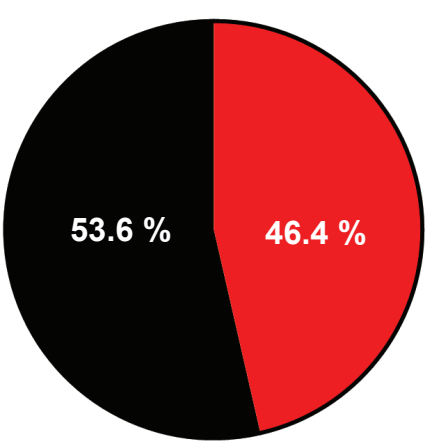

Bin1 ${ }^{\text {flfl }}$

Total $=237$ Bin1 mck-/- $^{\text {- }}$

E
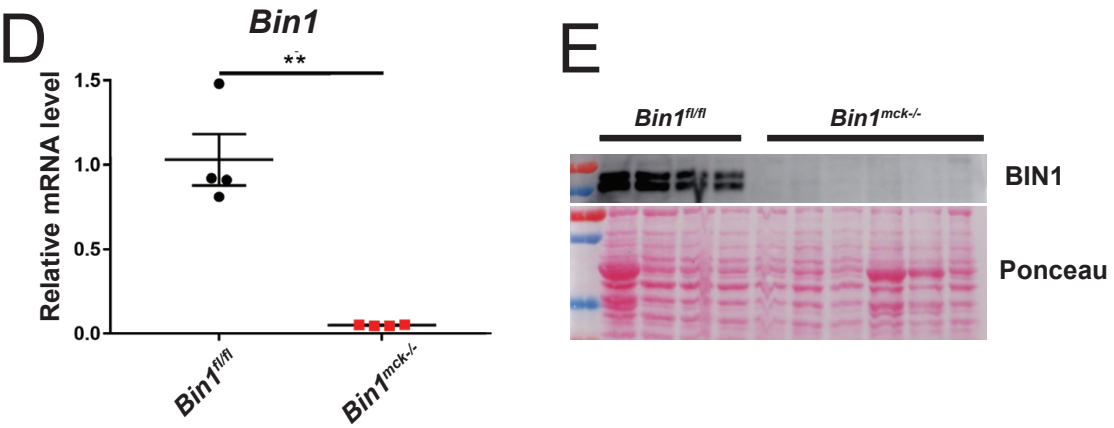

F
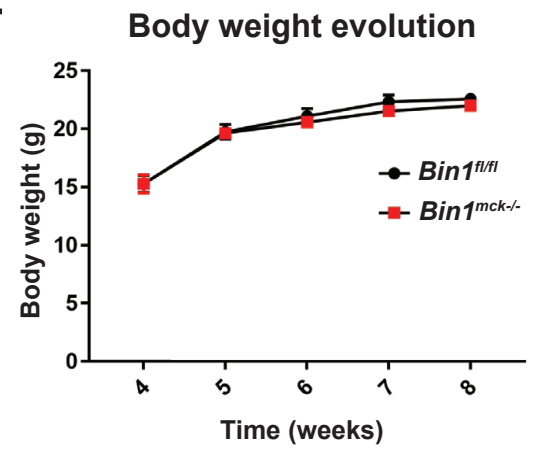

$G \quad$ Specific force
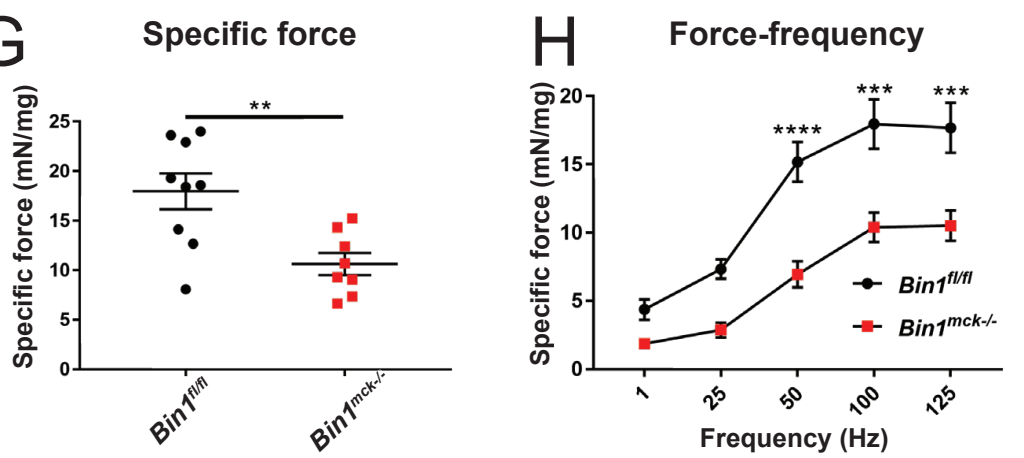

Figure 1. 


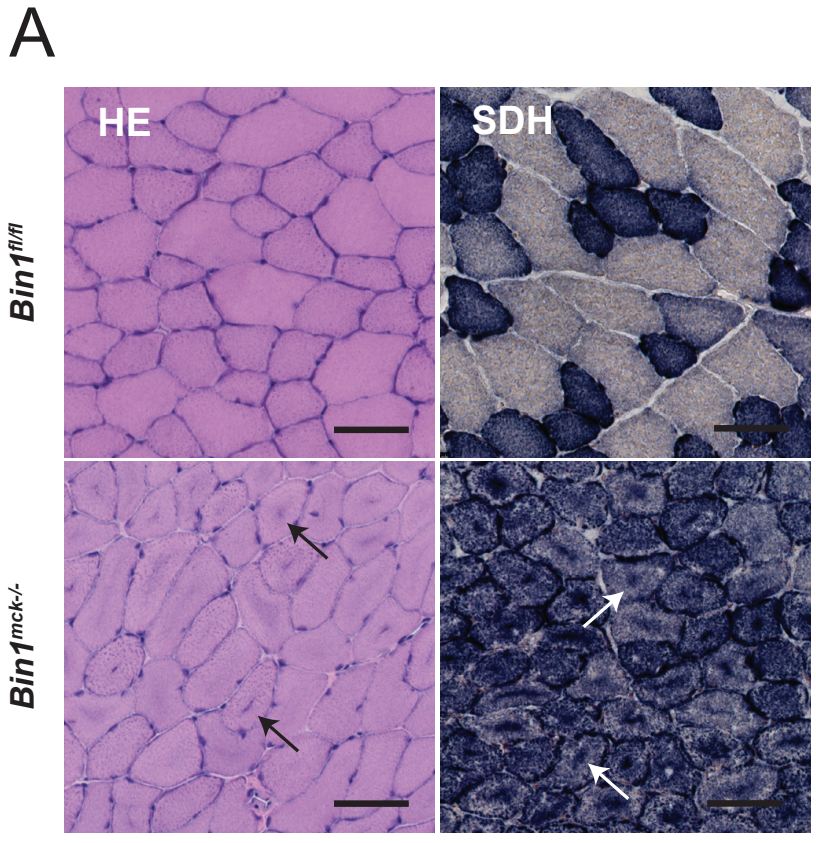

B

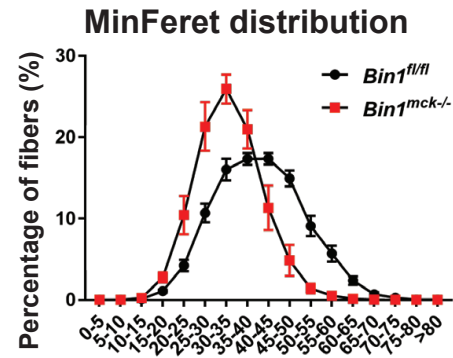

C

Percentage of large fibers
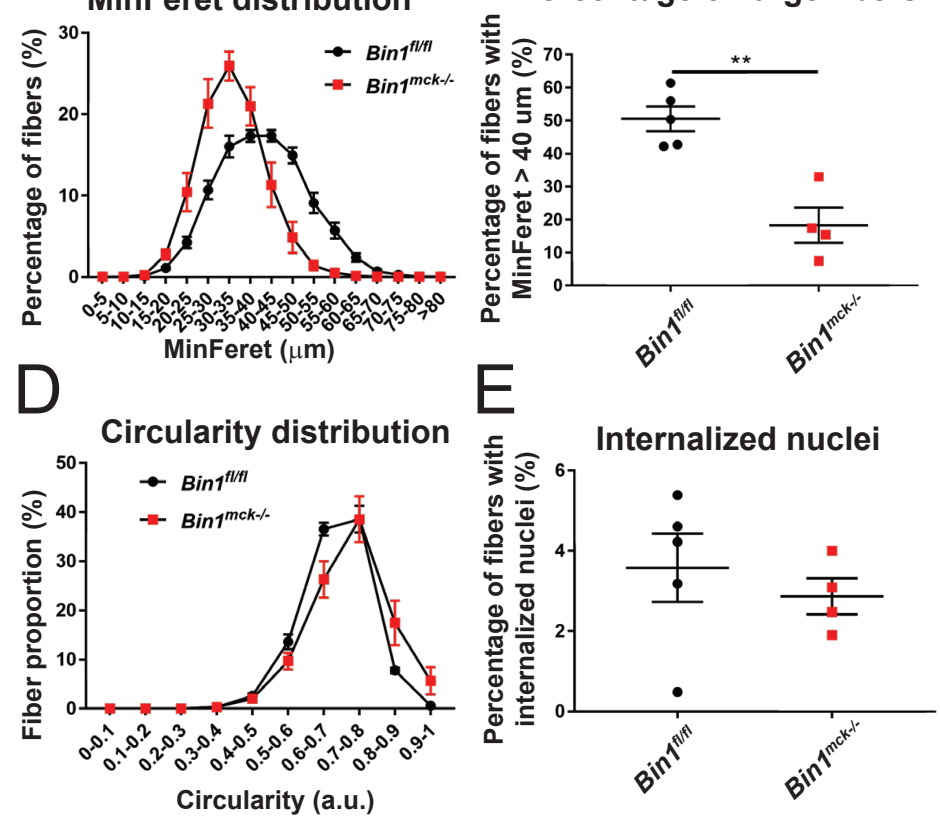

Figure 2. 
A

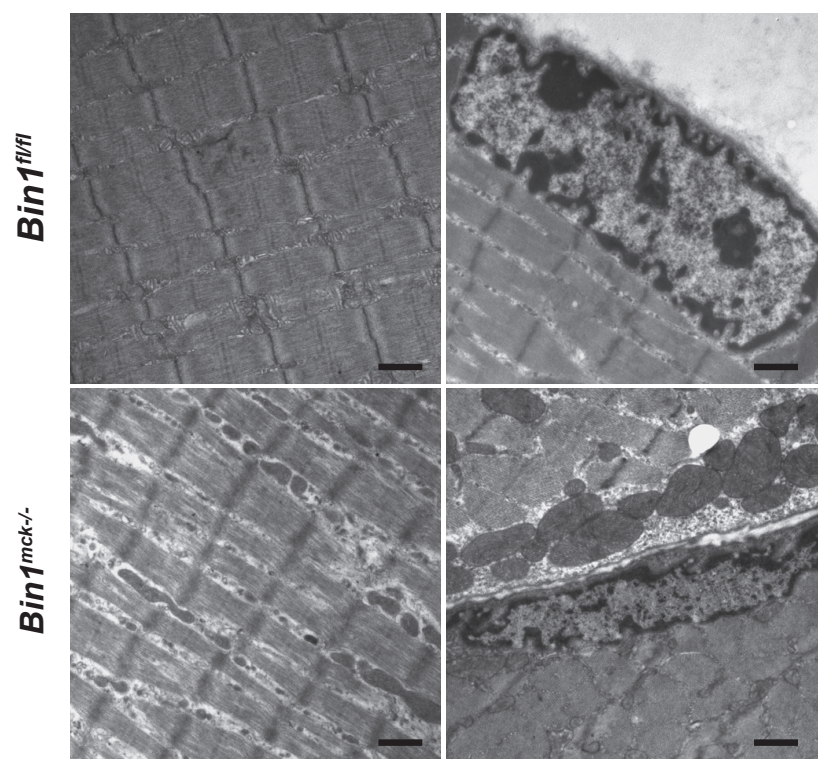

C

Prohibitin protein expression
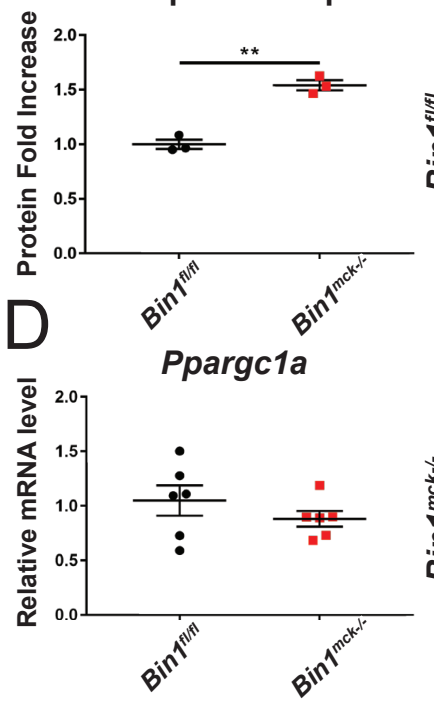

B

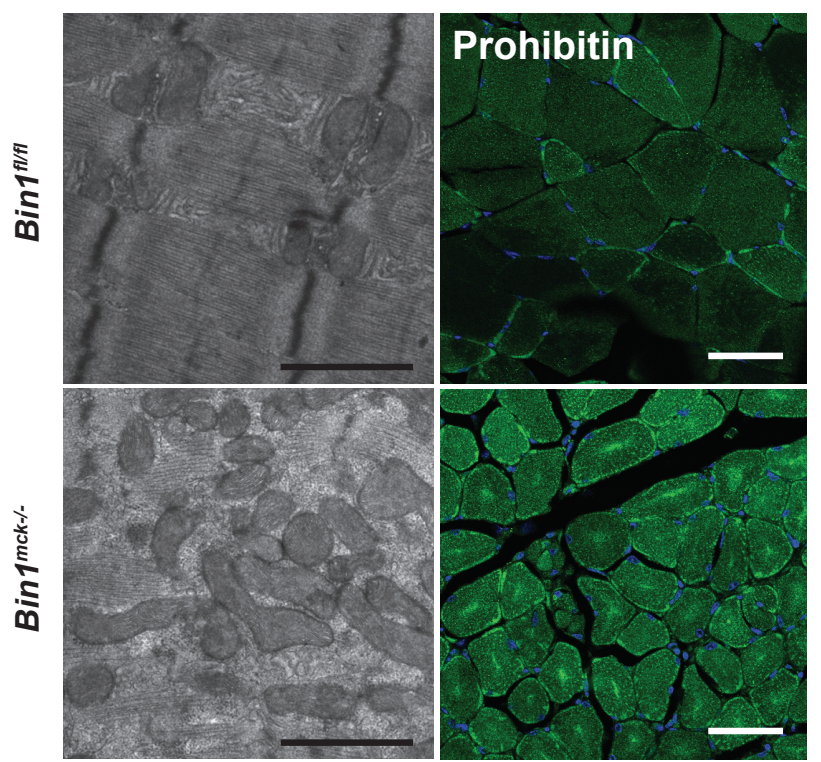

F
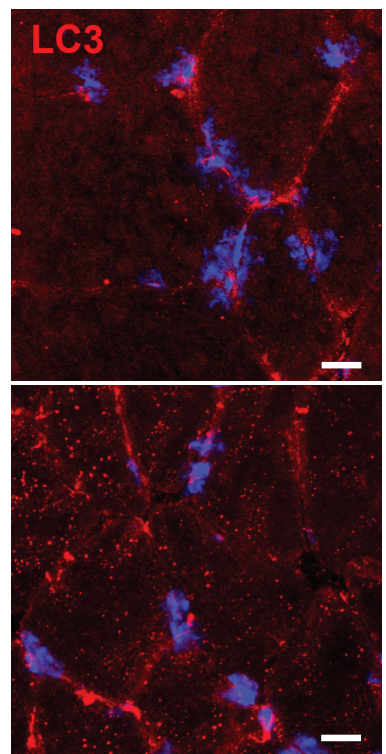

P62 protein expression

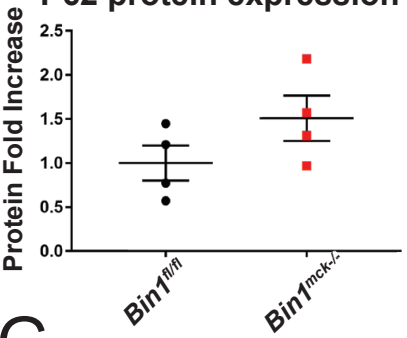

LC3 II protein expression

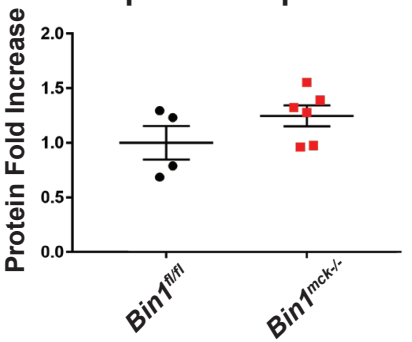

Figure 3. 


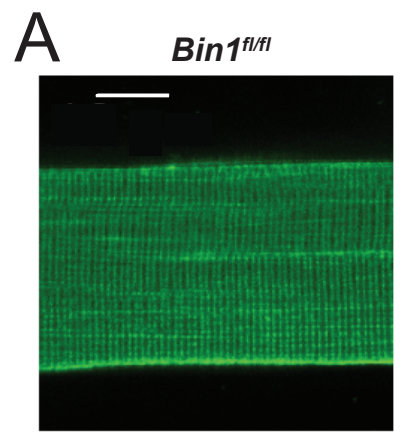

\section{Bin1 ${ }^{m c k-/-}$}

B

T-tubule network
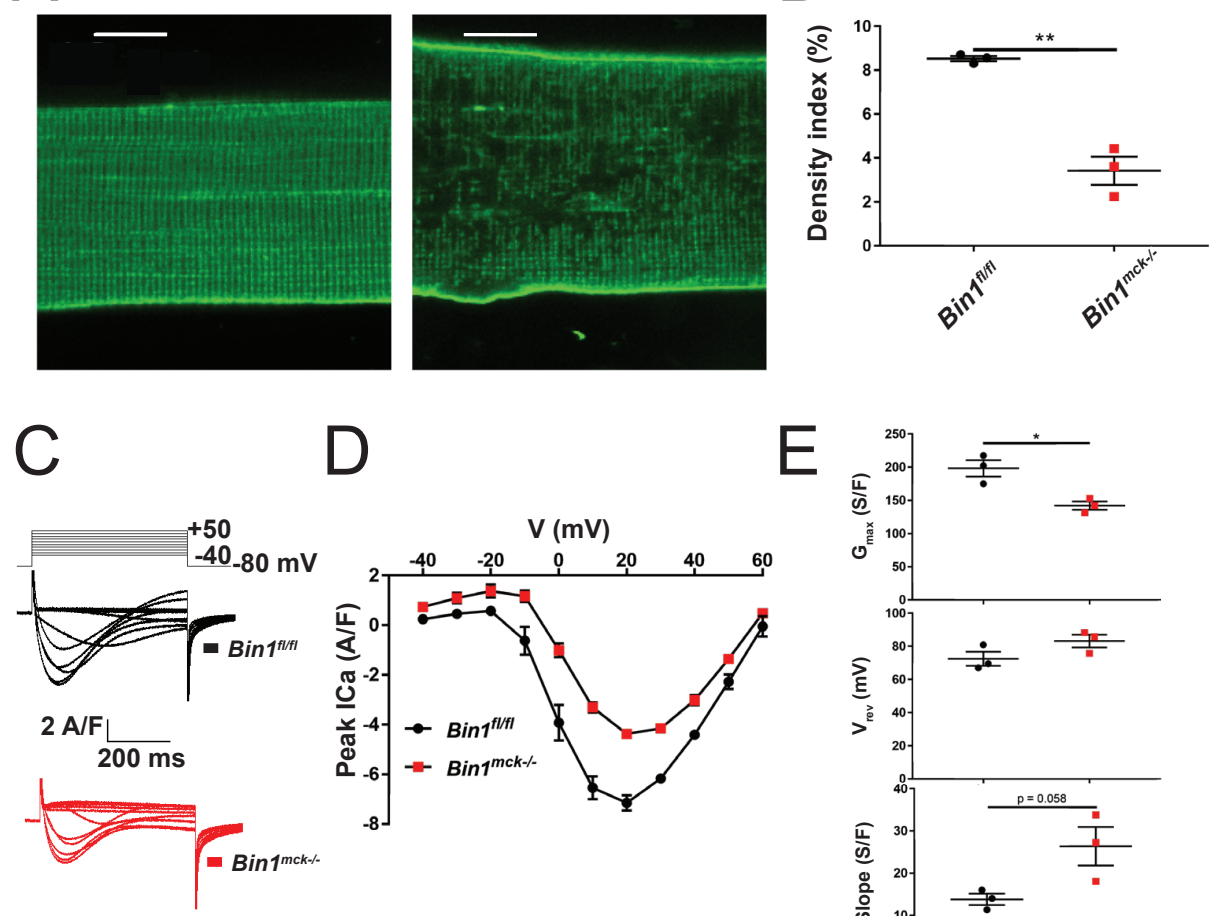

E

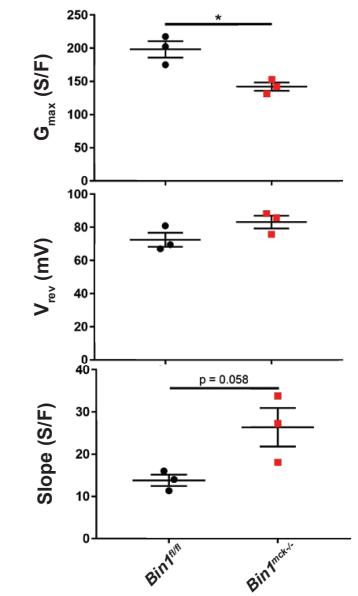

F

G

$\mathrm{H}$

Maximum

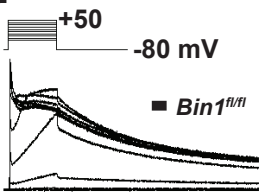

$\mathrm{F}_{0} \mathrm{~L}_{400} \mathrm{~ms}$
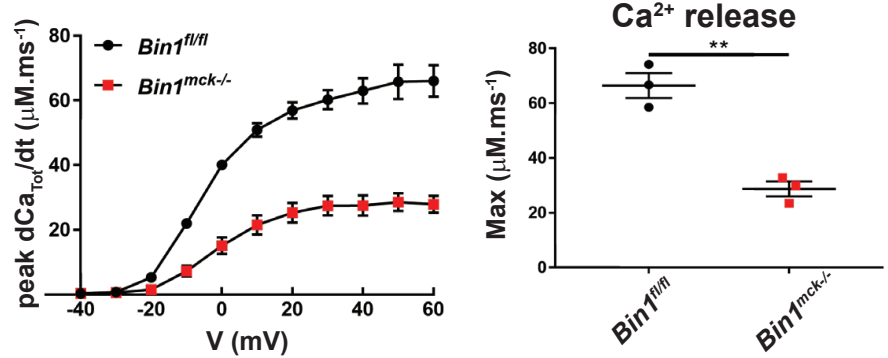

Figure 4. 


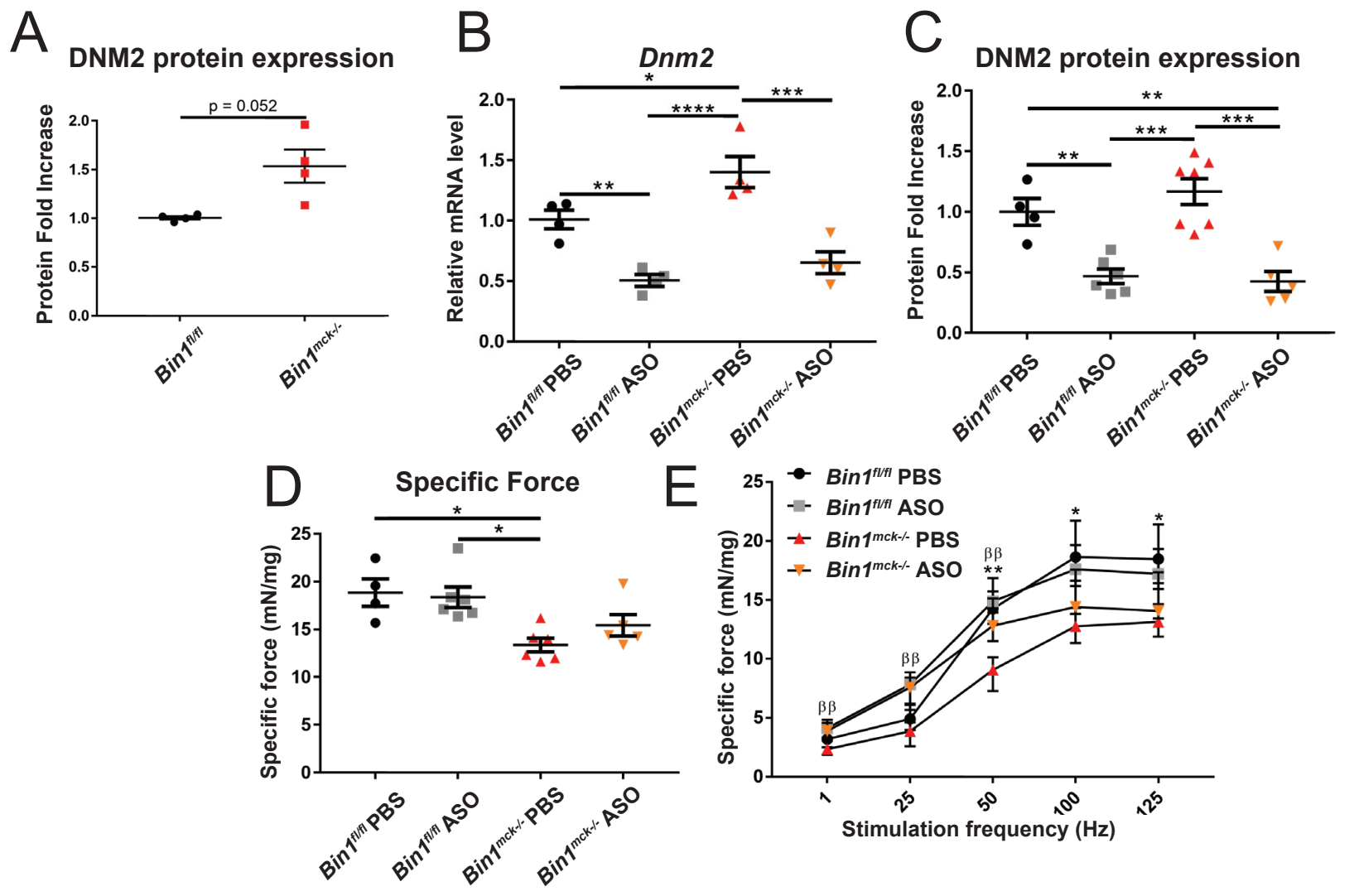

Figure 5. 
A

Bin $^{\text {flffl }}$ PBS
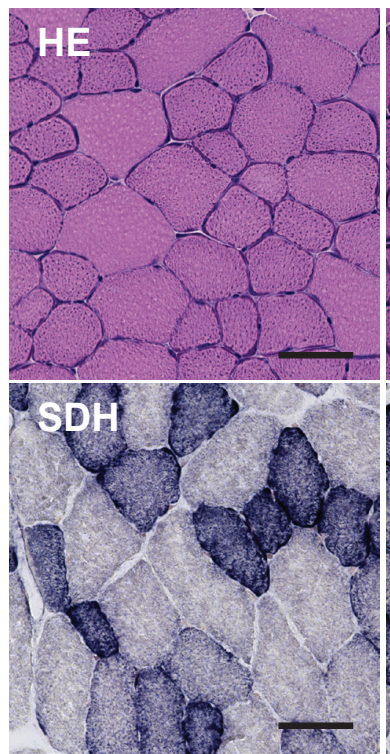

B

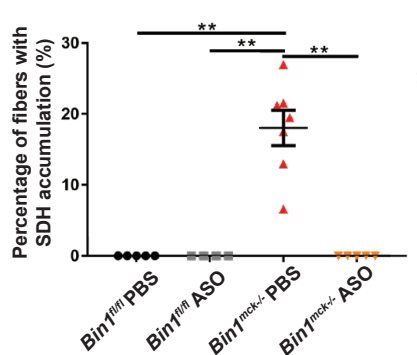

Bin1 $^{\text {fl/fI }}$ ASO
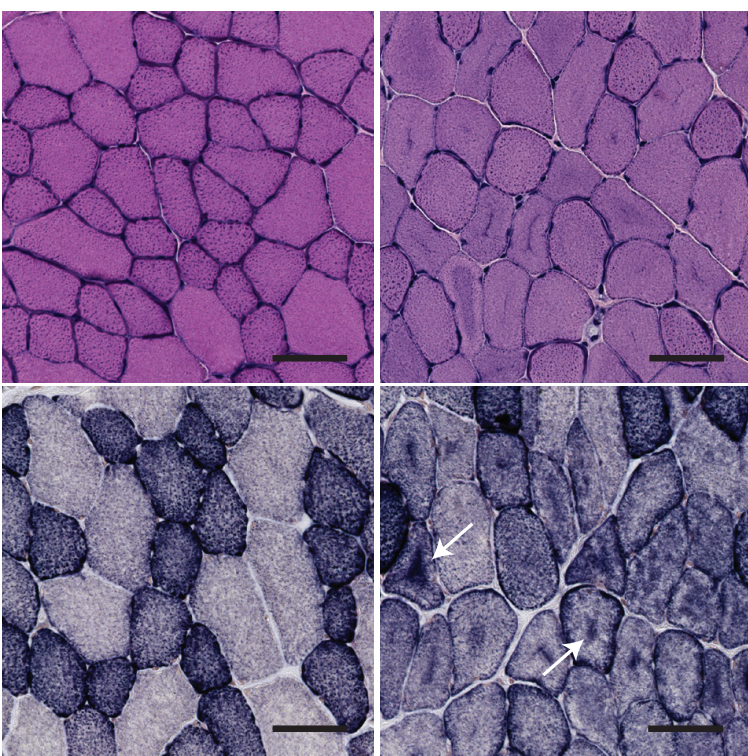

D
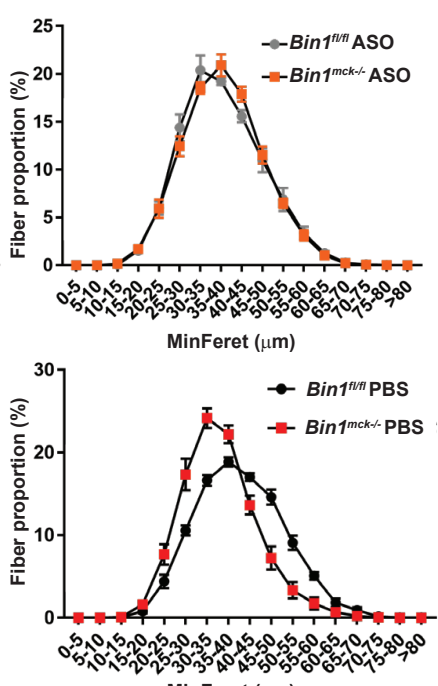

MinFeret ( $\mu \mathrm{m})$

Bin 1 $^{\text {mck-/- }}$ PBS

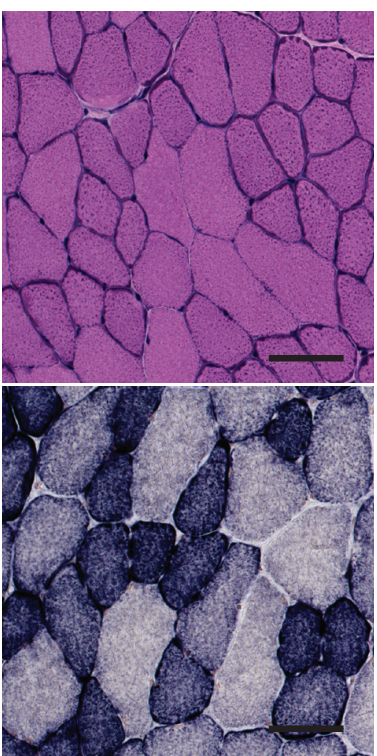

E Percentage of large fibers
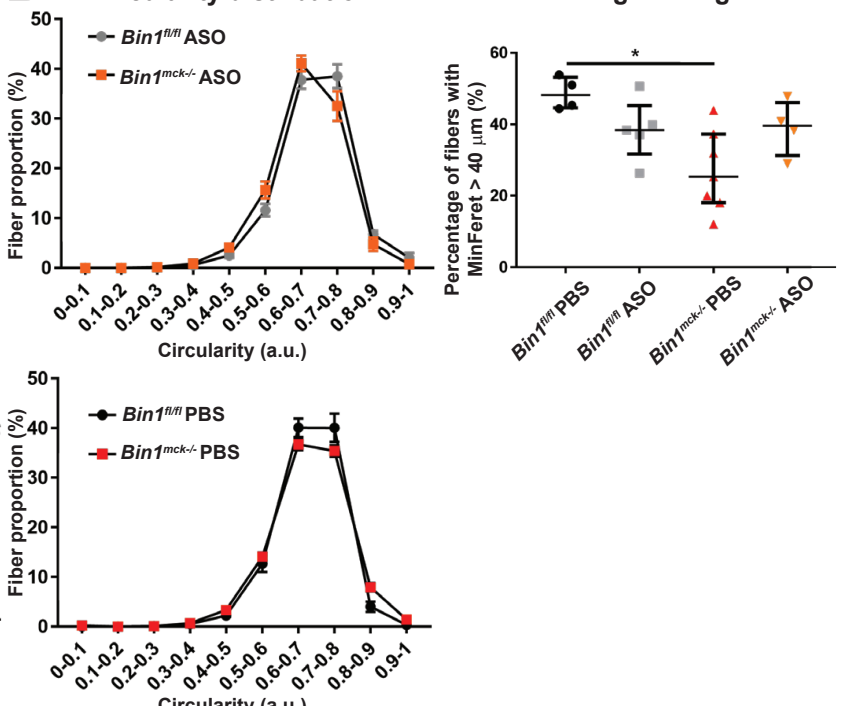

Figure 6. 


\section{Supplementary Information}

\section{Supplemental Figure S1. Body and muscle weights of Bin1 ${ }^{\text {mck-l- }}$ are affected in late adulthood.}

(A) TA, gastrocnemius and heart weight ratio to total body weight at 8 weeks of age ( $n=8-9$; Student's t test). (B) Body weight of Bin $1^{f l f l}$ and Bin $I^{m c k-/}$ mice at 4 months and 12 months of age ( $n=3-7$; Student's t test). (C-D) TA and gastroncnemius weight ratio to total body weight at 4 and 12 months of age ( $n=3-7$; Student's $t$ test for 4 months TA and 12 months gastrocnemius and Mann-Whitney test for 4 months gastrocnemius and 12 months TA). $* * * P<0.001$.

Supplemental Figure S2. General locomotor performances and muscle force in Bin1 $1^{\text {mck-l- }}$ mice. (A) Hanging test evolution from 4 to 8 weeks old with every mouse tested three times ( $n=8$ 9; two-way ANOVA and Bonferroni post hoc test). (B-C) and latency time in treadmill exercise exhaustion test at 4 months of age ( $n=6-7$; Student's $t$ test). (D) Latency time to grab the wire with hindlimbs in string test for Bin $f^{f l f l}$ and Bin $1^{\text {mck-l- }}$ mice at 7 weeks of age (n=8-9; Student t-test with Welch's correction). (E) Total latency time to fall attained in 4 consecutive days on rotarod test at 6 weeks of age ( $n=8-9$, Student t-test with Welch's correction for each day independently). (F) Maximal absolute force produced by TA ( $\mathrm{n}=8-9$; Student's $\mathrm{t}$ test). (G) Specific force produced when 4 months old Bin $1^{f l f l}$ and Binl ${ }^{\text {mck-l }}$ mice are stimulated at increasing frequencies ( $\mathrm{n}=5-7$; Student's $\mathrm{t}$ test for 25, 50, 100 and $125 \mathrm{~Hz}$ frequencies and Student t-test with Welch's correction for $1 \mathrm{~Hz}$ frequency). (H) Maximal specific force produced by 4 months old Bin $f^{f l / f l}$ and Binl ${ }^{\text {mck-l- }}$ mice (n=5-7; Student's t test). (I) Specific force produced when 12 months old Bin $f^{f l f l}$ and Bin ${ }^{\text {mck- }}$ '- mice are stimulated at increasing frequencies ( $n=3-6$; Student's t test for all frequencies). (J) Maximal specific force produced by 12 months old Bin $f^{f l f l}$ and Bin $1^{\text {mck-l- }}$ mice (n=3-6; Student's $\mathrm{t}$ test). $* * * P<0.001 ; * * P<0.01 ; * P<0.05$.

Supplemental Figure S3. Bin1 ${ }^{\text {mck-/ }}$ histopathological defects are also present in late adulthood. (A) Representative NADH and Gomori images of TA from Bin $f^{f l f l}$ and Bin $1^{\text {mck-l- }}$ mice at 8 weeks of age $(n=3)$. Scale bar $=50 \mu \mathrm{m}$. (B-C) Representative TA HE and SDH images from 4 and 12 months old Binl ${ }^{f l f l}$ and Binl ${ }^{\text {mck- } /-}$ mice $(\mathrm{n}=3-7)$. Scale bar=50 $\mu \mathrm{m}$. (D) MinFeret perimeter distribution of TA fibers from 4 and 12 months old Bin $1^{f l f l}$ and Binl $1^{m c k-l}$ mice $(\mathrm{n}=3-7)$. (E) Percentage of fibers with MinFeret diameter higher than $40 \mu \mathrm{m}$ in TA from 4 and 12 months Binl ${ }^{f l f f l}$ and Binl ${ }^{m c k-l-}$ mice (n=3-7; Student's $\mathrm{t}$ test). (F) Percentage of fibers with internalized nuclei in TA from 4 and 12 months Bin $I^{f l f l}$ and Bin $1^{m c k-/}$ mice (n=3-7; Student's $t$ test). (G) Rate 
of TA fibers with accumulation of SDH staining in 4 months and 12 months old mice ( $\mathrm{n}=3-7$; Student's t test for 12 months and Mann-Whitney test for 4 months). $* * * * P<0.0001 ; * * * P<0.001$; $* * P<0.01 ; * P<0.05$.

Supplemental Figure S4. Histopathological defects are present in skeletal but not cardiac muscles from Bin1 ${ }^{m c k-/}$ mice. (A) Representative HE images from Binl flfl and Binl ${ }^{m c k-/-}$ gastrocnemius and heart at 8 weeks of age $(n=3)$. Scale bar $=50 \mu \mathrm{m}$. (B) Representative HE images from heterozygous Bin $1^{f l /+}$ and Bin1 $1^{m c k+/-}$ TA $(\mathrm{n}=2)$. Scale bar=50 $\mu \mathrm{m}$. (C) Myosin heavy chain isoforms mRNA levels assessed by RT-qPCR. Corresponding fiber types are indicated in bracket ( $\mathrm{n}=6$; Student's t test for $M y h 7$ and Myh2 and Mann-Whitney test for Myh1 and Myh4). ${ }^{*} P<0.05$.

Supplemental Figure S5. Western blot analyses of mitochondria and autophagy markers in TA and gene expression of autophagic genes at 8 weeks of age. Western blot for (A) prohibitin and (B) P62 and LC3 protein levels normalized to Ponceau S staining. (C) Relative TA mRNA levels of autophagy genes Map1lc3a, Map1lc3b and Sqstm1 encoding LC3 isoforms and P62 (n=46; Student's t test). ${ }^{*} P<0.05$.

Supplemental Figure S6. FDB histology, half-activation voltage ( $\left.\mathrm{V}_{0.5}\right)$ and steepness factor (k) of the voltage dependence of isolated fibers from FDB. (A) Representative FDB HE and SDH images from 8 weeks old Binl $1^{f l f l}$ and Binl $1^{m c k-/}$ mice $(n=3-5)$. Scale bar=50 $\mu$ m. (B, top) MinFeret perimeter distribution of TA fibers from 4 and 12 months old Bin $1^{\text {flfl } l}$ and Bin $1^{\text {mck-/ }}$ mice ( $\mathrm{n}=3-5$; Student's t test). (B, middle) Percentage of fibers with MinFeret diameter higher than 30 $\mu \mathrm{m}$ in FDB from 8 weeks old Binl $1^{f l f l}$ and Bin1 $1^{m c k-/}$ mice (n=3-5; Student's t test). (B, bottom) Percentage of fibers with internalized nuclei in FDB from 8 weeks Bin $1^{f l f l}$ and Bin $1^{\text {mck-l- mice }}$ $\left(\mathrm{n}=3-5\right.$; Student's t test). (C) Half-activation voltage $\left(\mathrm{V}_{0.5}\right)$ and steepness factor $(\mathrm{k})$ of the voltage dependence of Cav1.1 $\mathrm{Ca}^{2+}$ current ( $\mathrm{n}=3$ mice per genotype, 5-6 fibers analysed per mice; Student's t test with and without Welch's correction, respectively). (D) Half-activation voltage $\left(\mathrm{V}_{0.5}\right)$ and steepness factor $(\mathrm{k})$ of SR $\mathrm{Ca}^{2+}$ release $(\mathrm{n}=3$ mice per genotype, 5-6 fibers analysed per mice; Student's t test).

Supplemental Figure S7. DNM2 protein levels in TA from PBS- or ASO-treated Bin1 ${ }^{\text {mck-/- }}$ mice at 8 weeks of age. (A) DNM2 western blotting in Bin $1^{f l f l}$ and Bin $1^{\text {mck-l- }}$ TA with Ponceau S staining as loading control. (B) Western blot membranes labelled for DNM2 and BIN1 in PBS or ASO-treated Binl $1^{f l f l}$ and Bin $1^{\text {mck-/ }}$ mice with Ponceau S staining as loading controls. 
Supplemental Figure S8. Altered TA maximal force and histology in Bin ${ }^{\text {mck-l- }}$ mice at 8 weeks of age. (A) Maximal absolute force produced by TA of PBS or ASO-treated Bin $1^{f l f l}$ and Bin1 ${ }^{m c k-1}$ mice (n=4-6; Kruskal-Wallis with Dunn's post hoc test). (B) Representative NADH images of TA from PBS- or ASO-treated Bin $1^{f l f l}$ and Bin $1^{m c k-/}$ mice. Arrows point to abnormal central accumulation of the staining $(n=4-7)$. Scale bar=50 $\mu \mathrm{m}$. (C) Representative desmin and TOMM20 immunofluorescence pattern in PBS and ASO-treated Binl ${ }^{m c k-/}$ mice $(\mathrm{n}=3)$. Scale bar $=50 \mu \mathrm{m}$. (D) Percentage of TA fibers with desmin or TOMM20 mislocalization at 8 weeks ( $n=3$; one-way ANOVA with Tukey's post hoc test). (E) Myosin heavy chain mRNA levels assessed by RT-qPCR. Corresponding fiber types are indicated in bracket ( $\mathrm{n}=4$; one-way ANOVA with Tukey's post hoc test for Myh2, Myh4 and Myh7 and Kruskal-Wallis with Dunn's post hoc test for $M y h l) . * * P<0.01 ; * P<0.05$.

\section{Supplemental Table S1. List of primers used for RT-qPCR.}




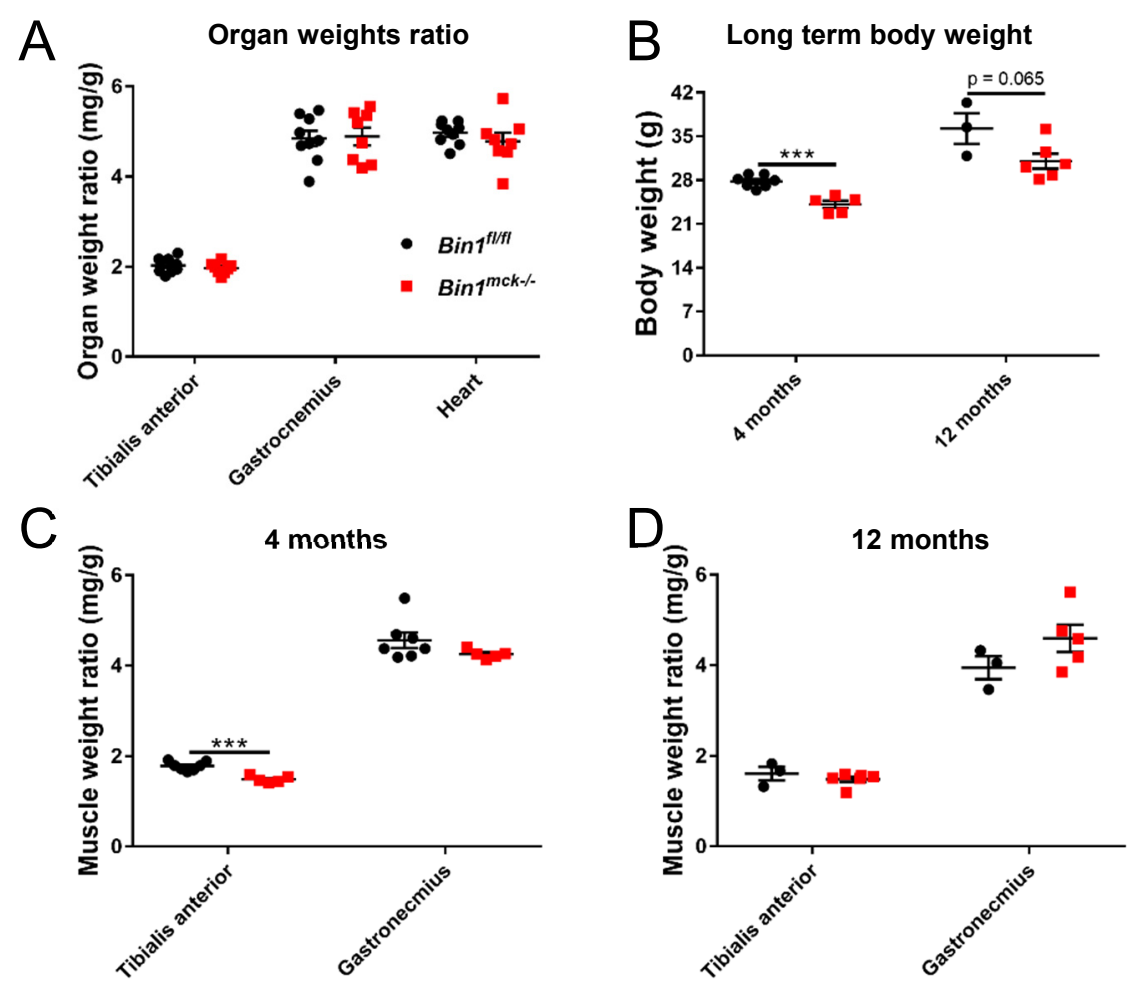

Supplemental Figure S1. 

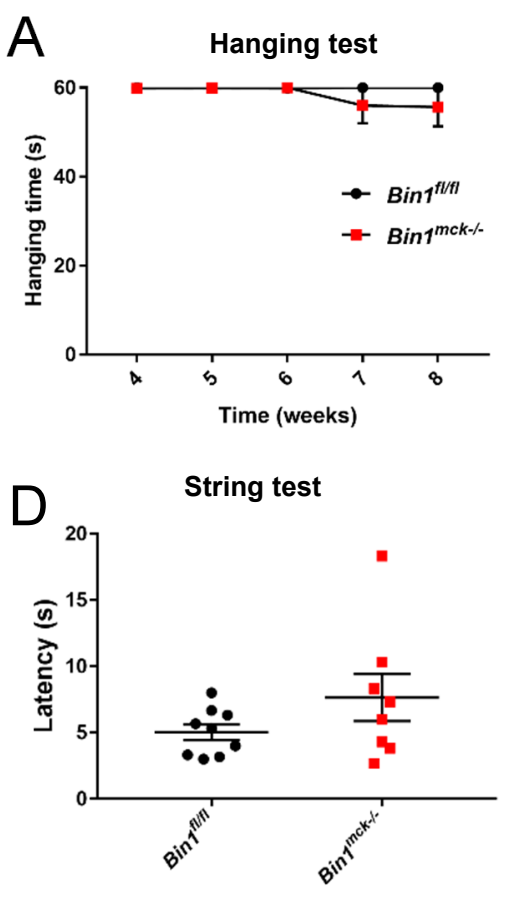

G Force-frequency 4 months
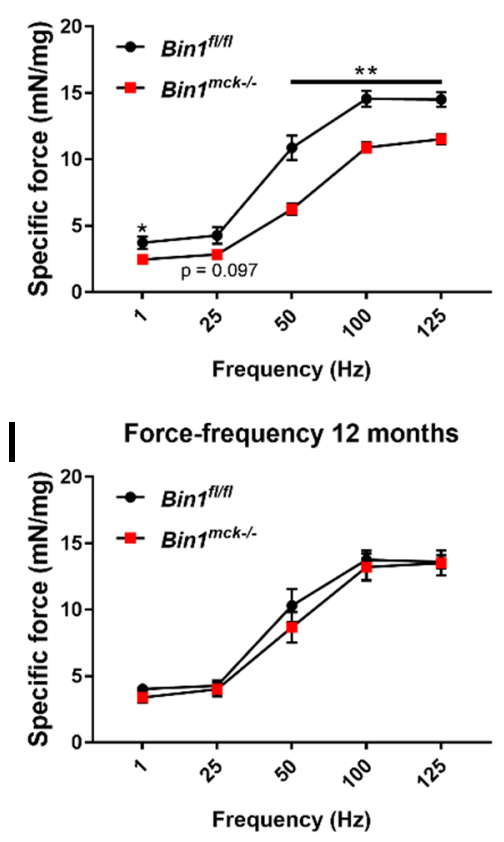
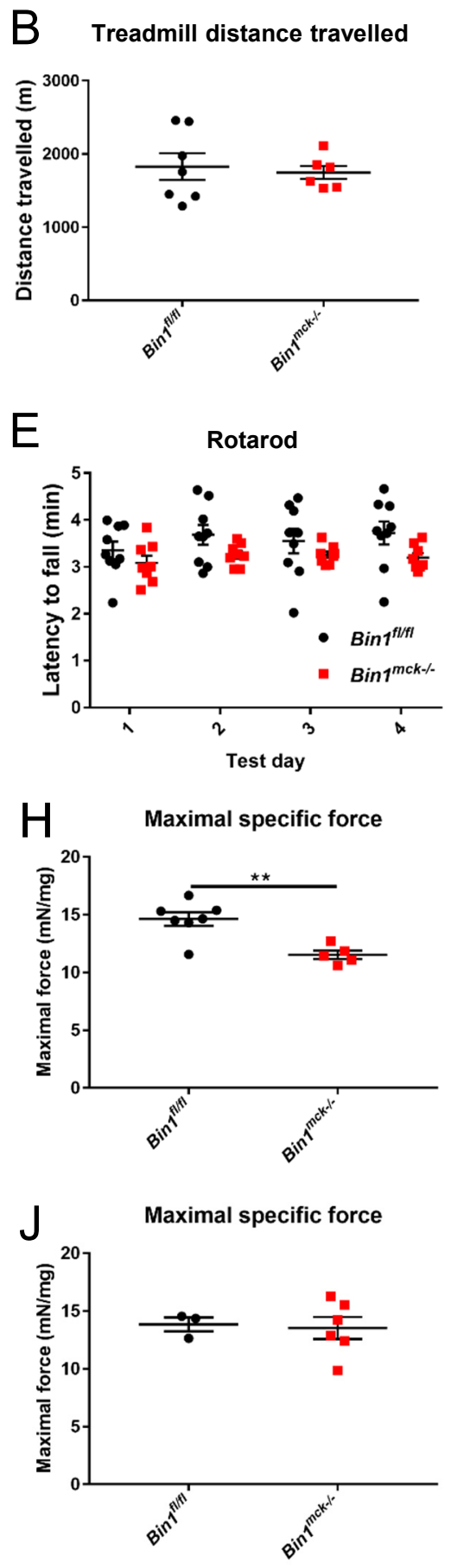

C Treadmill latency time
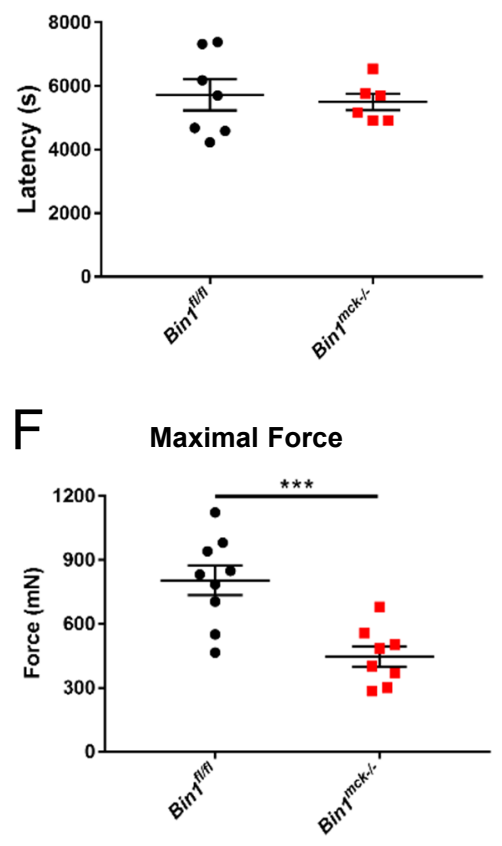

Supplemental Figure S2. 


\section{Supplemental Figure S3.}

A Tibialis anterior

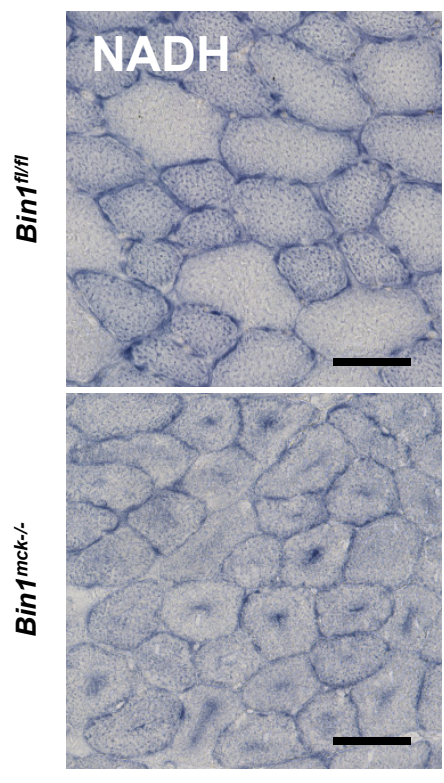

C Tibialis anterior

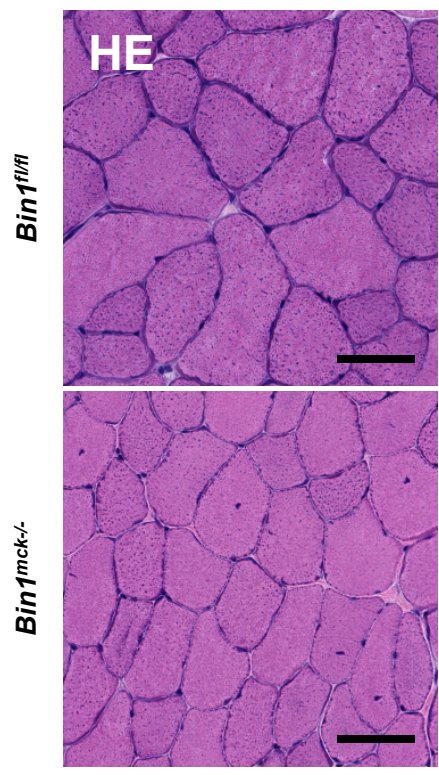

Tibialis anterior

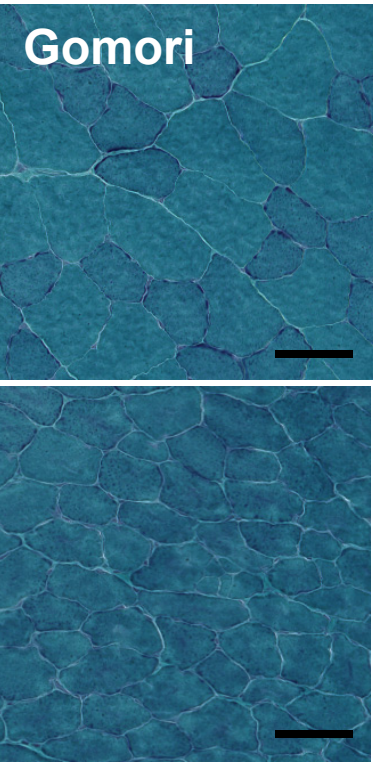

Tibialis anterior

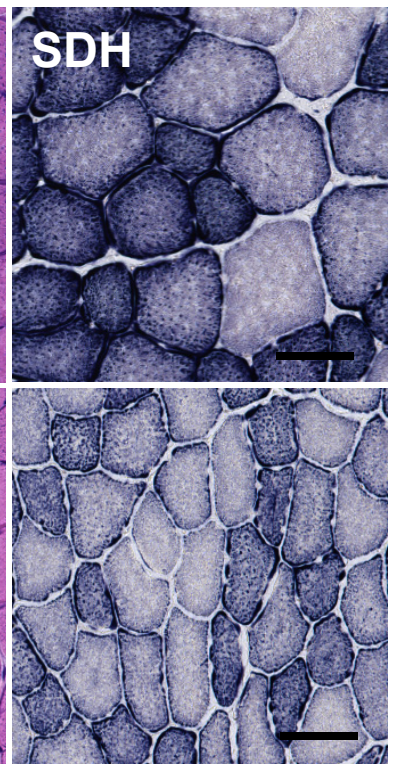

B
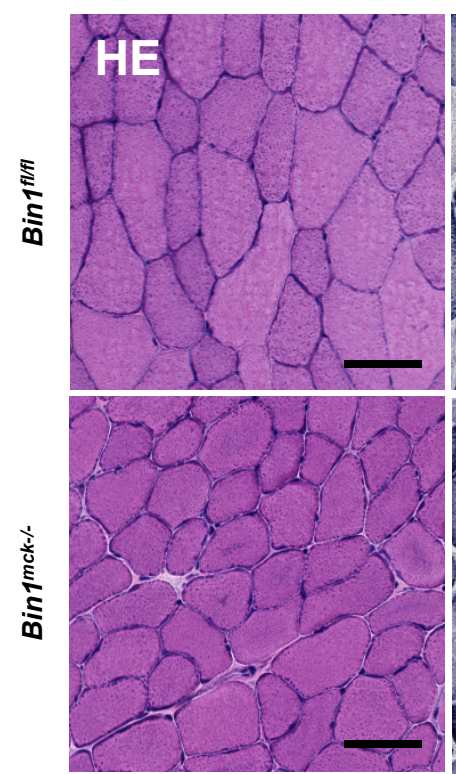

D

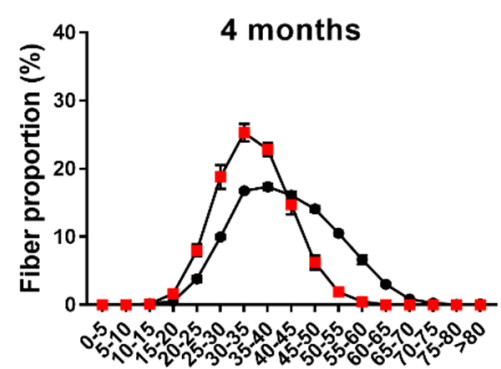

MinFeret $(\mu \mathrm{m})$

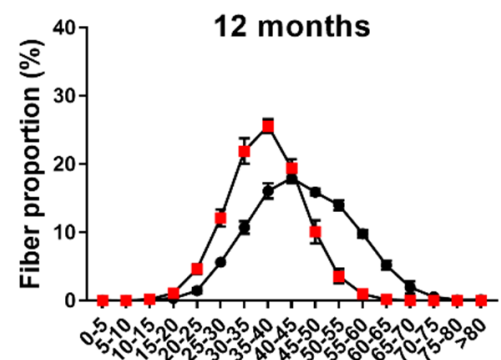

MinFeret $(\mu \mathrm{m})$

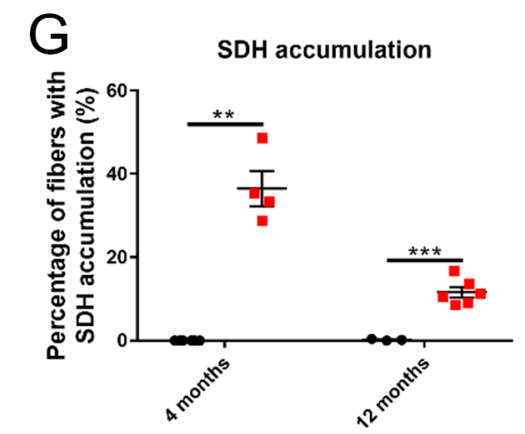

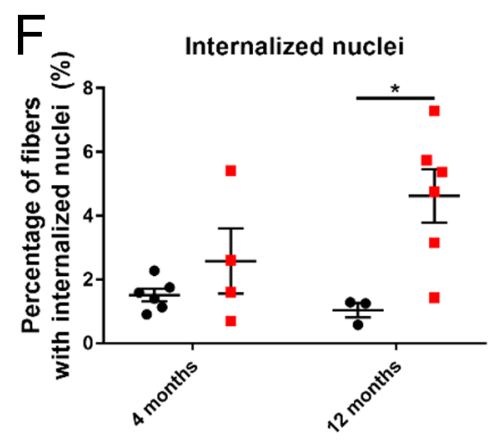
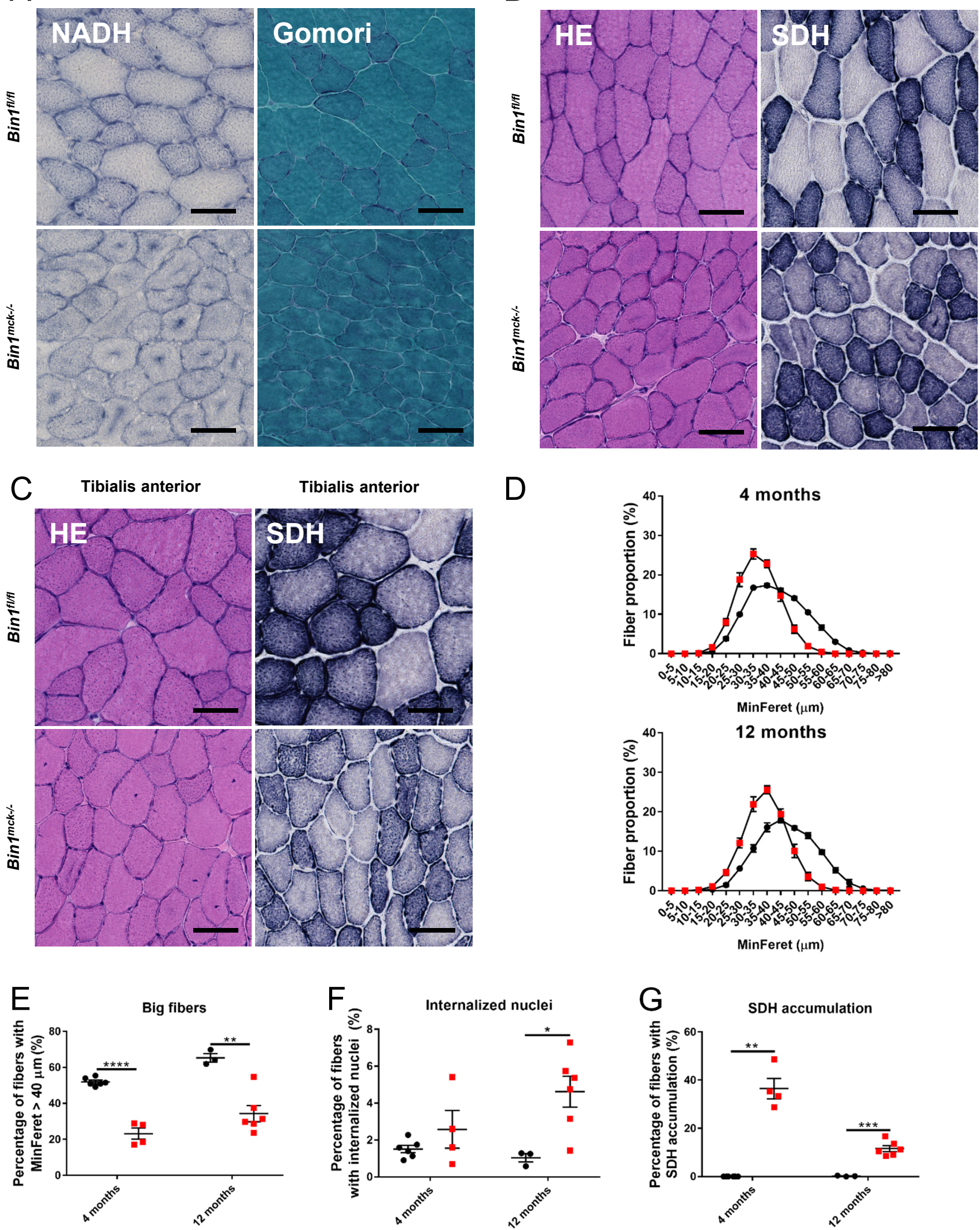
A Gastrocnemius
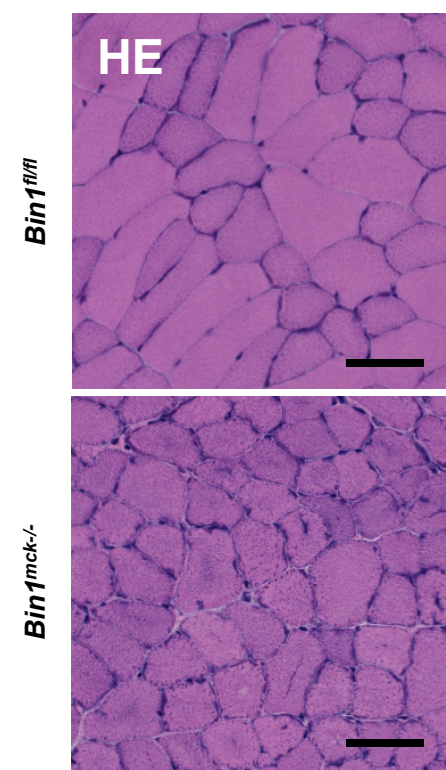

C

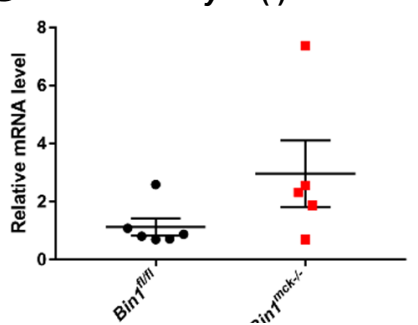

Myh4 (IIb)

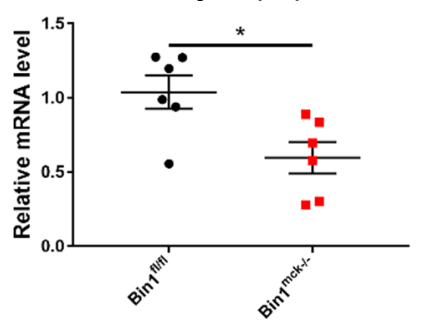

Heart
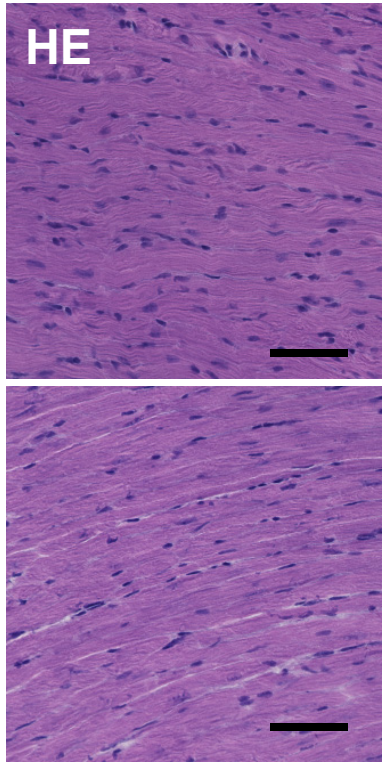

Myh2 (Ila)

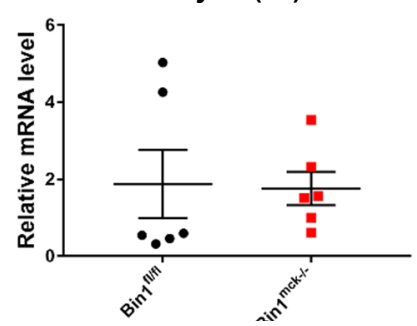

Myh1 (IIx)

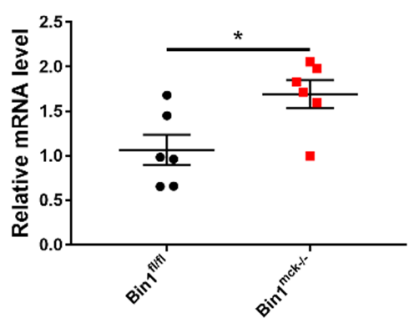

B
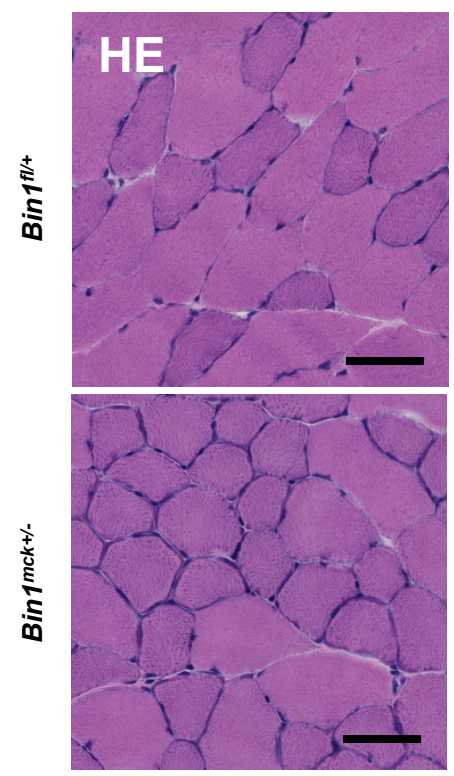

Supplemental Figure S4. 

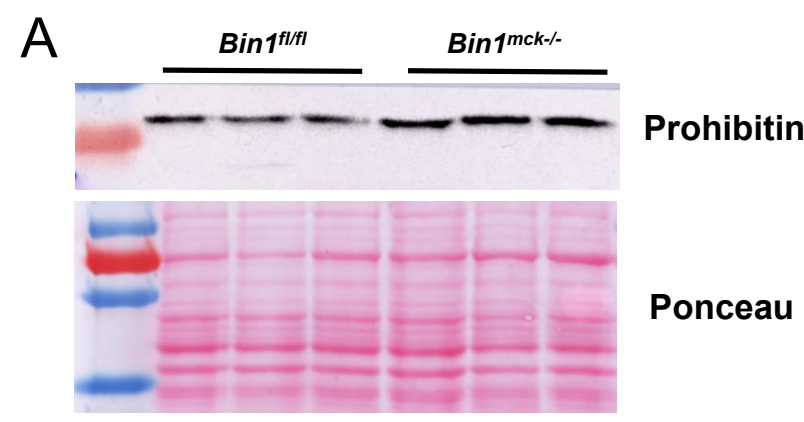

B

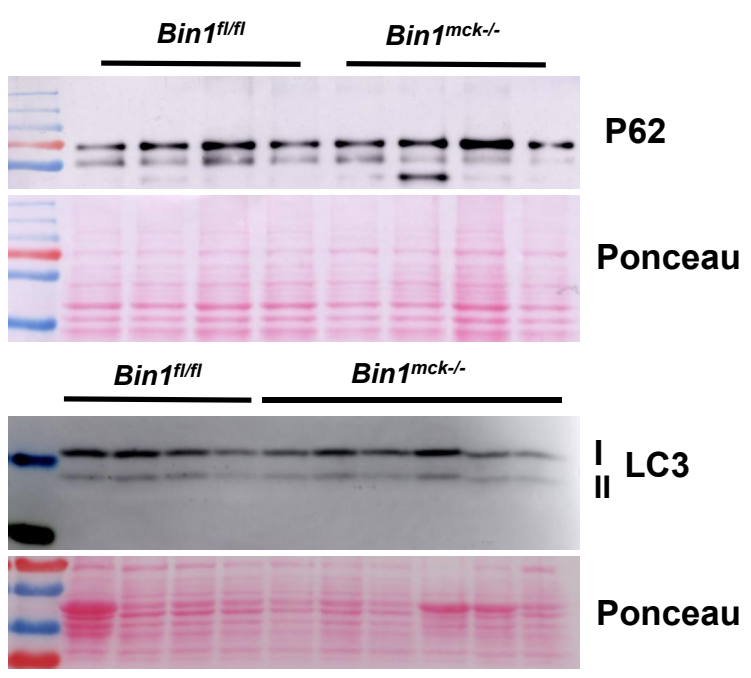

C

Autophagy genes

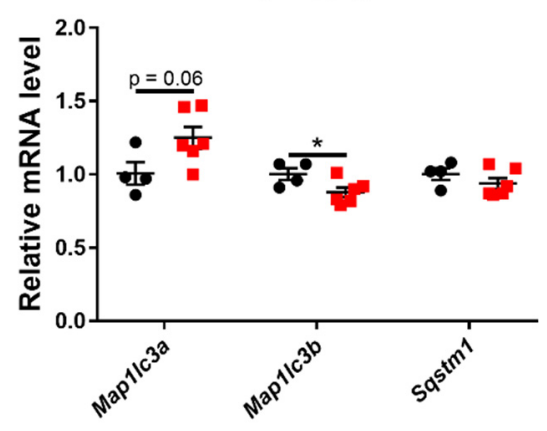

Supplemental Figure S5. 
A

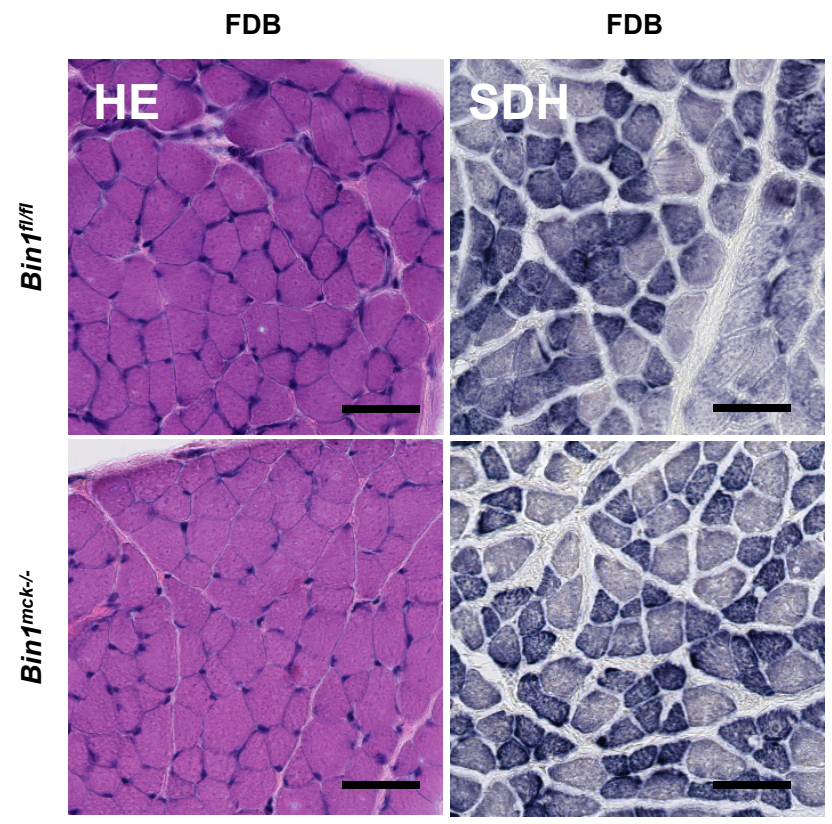

C Half-activation voltage
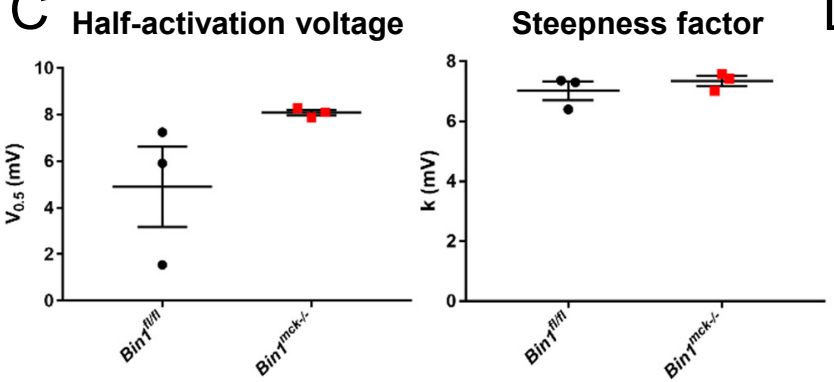

$B$

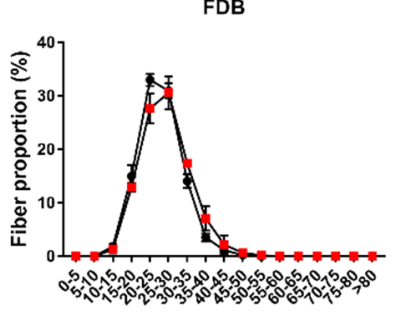

MinFeret $(\mu \mathrm{m})$
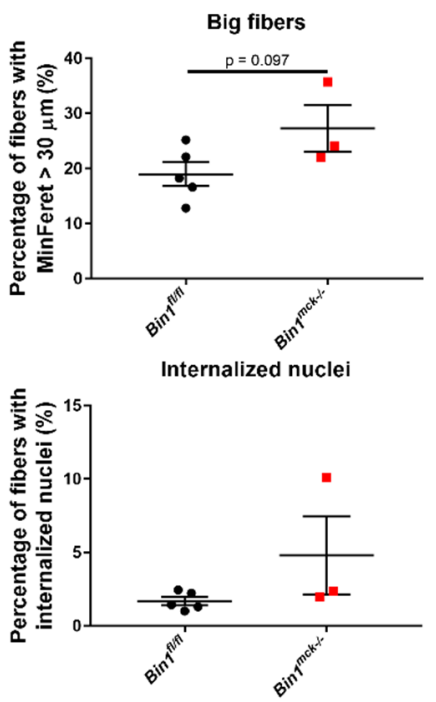

D Half-activation voltage Steepness factor
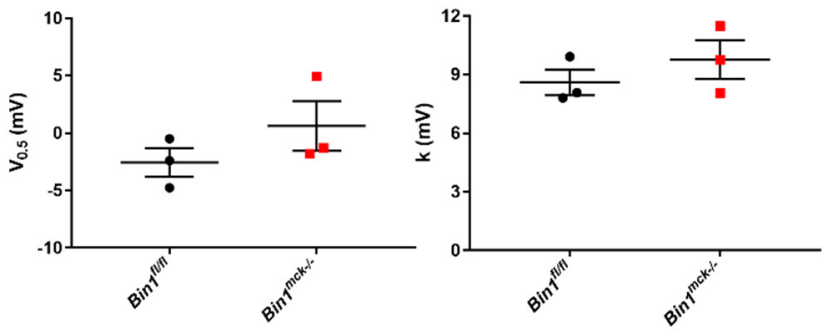

Supplemental Figure S6. 

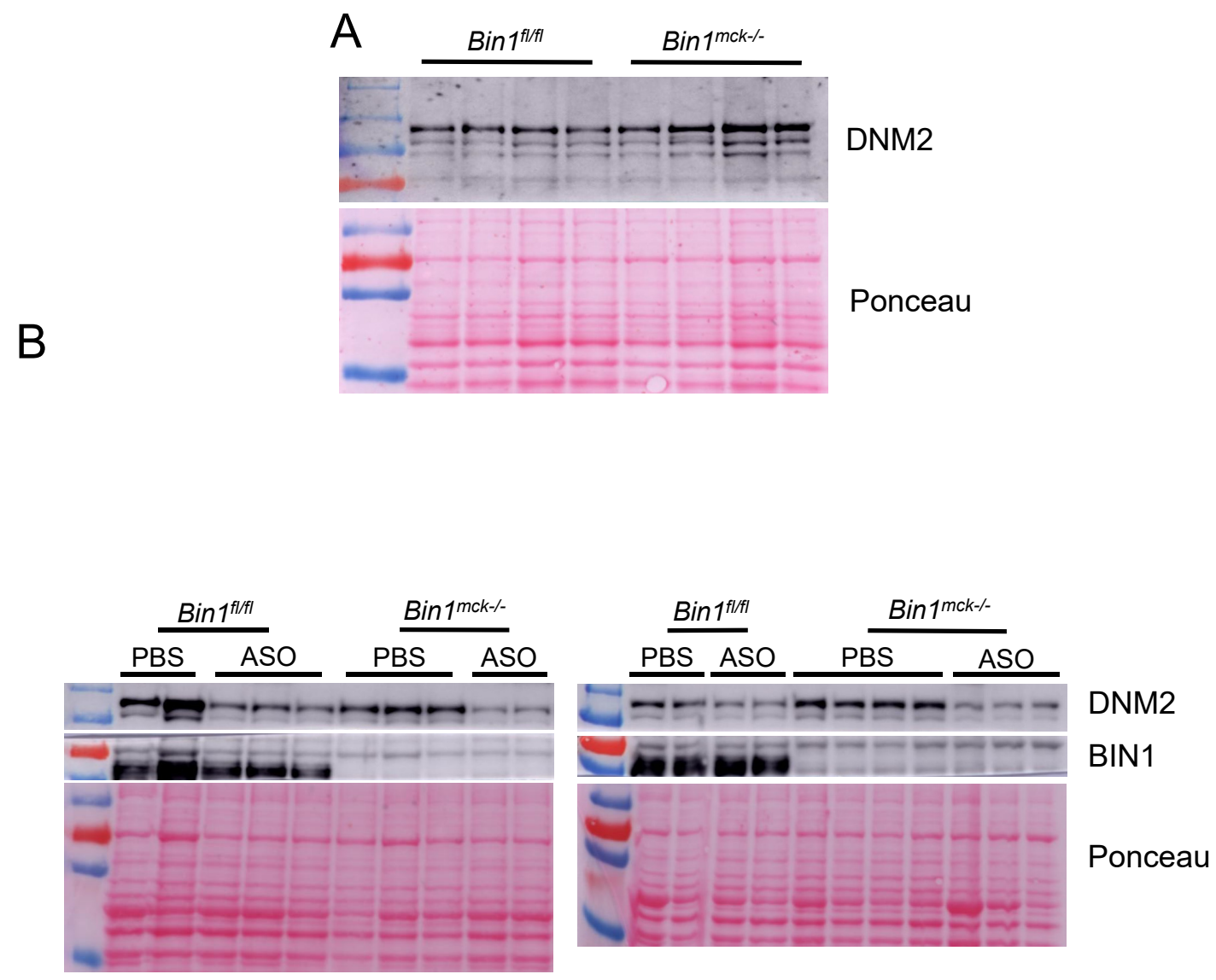

Supplemental Figure S7. 
A

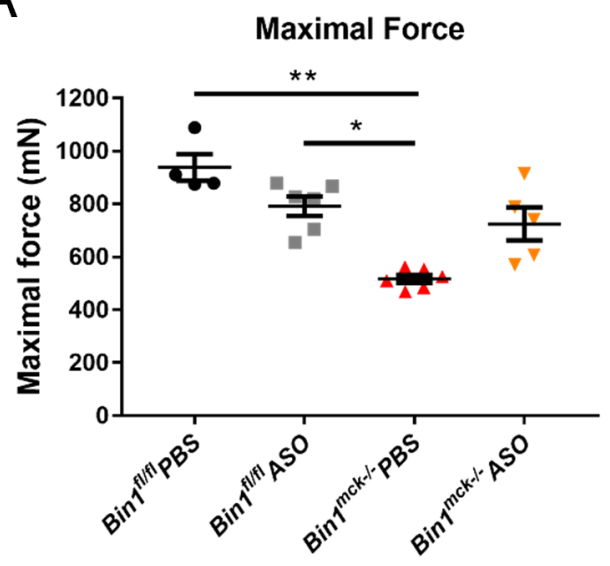

B

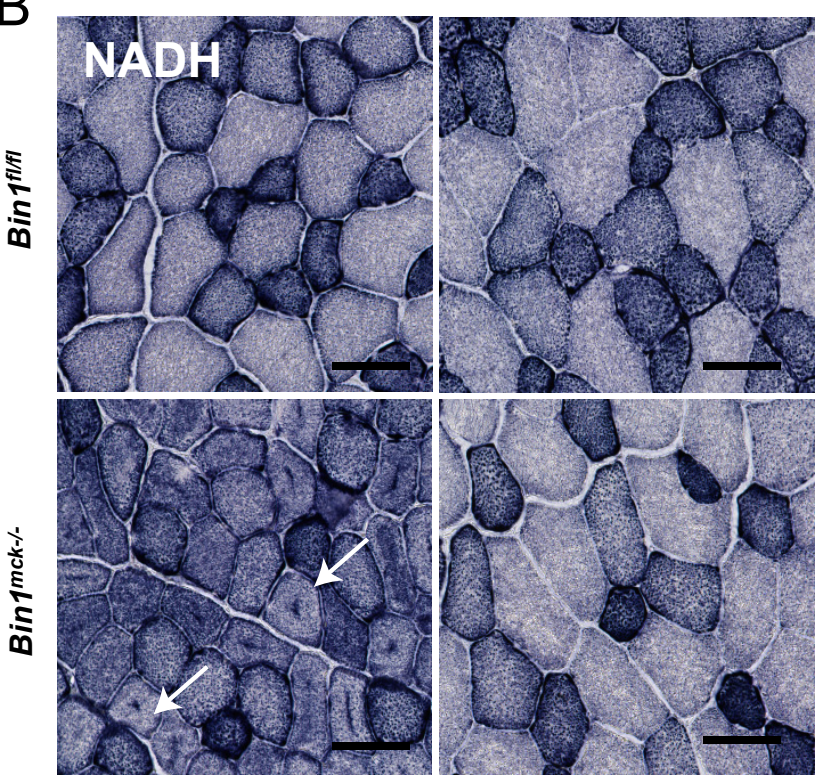

C
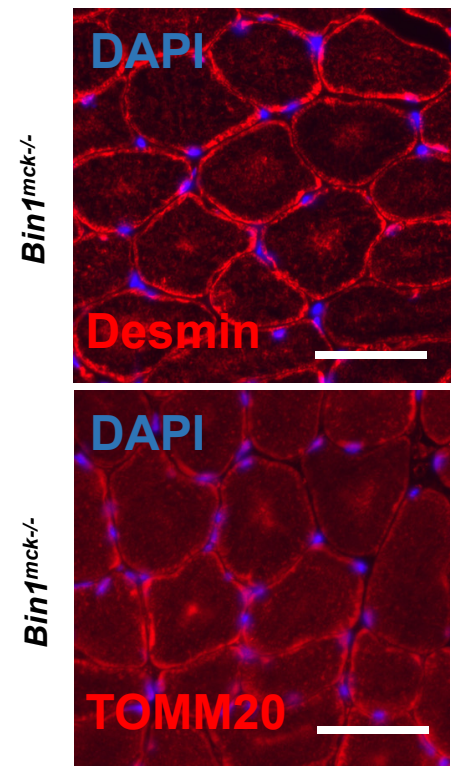

E $\quad M y h 7$ (I)

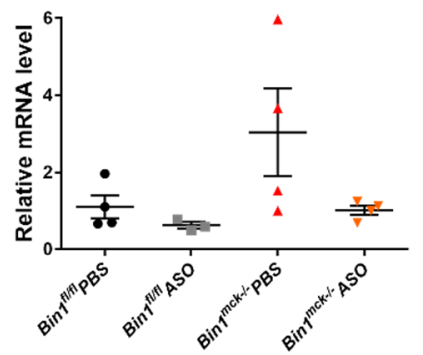

ASO

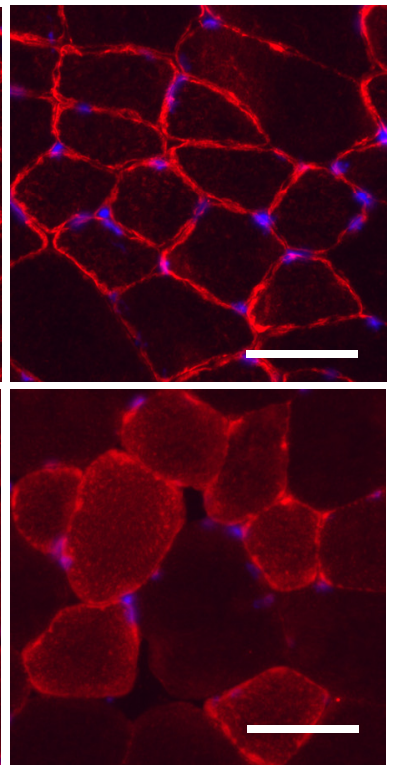

Myh2 (Ila)
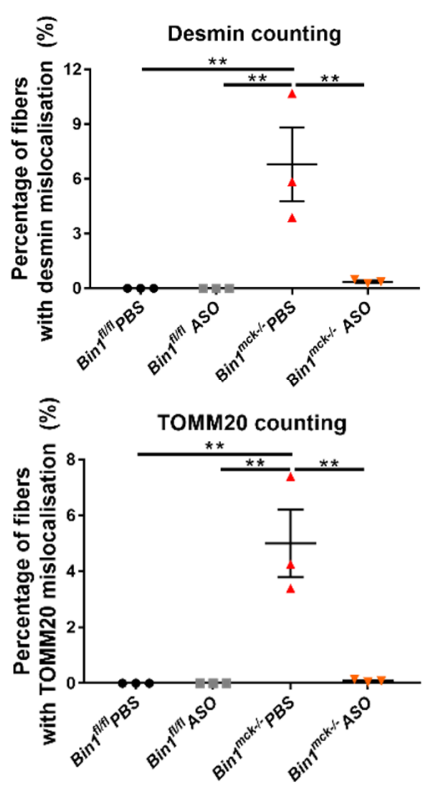

Myh1 (IIx)

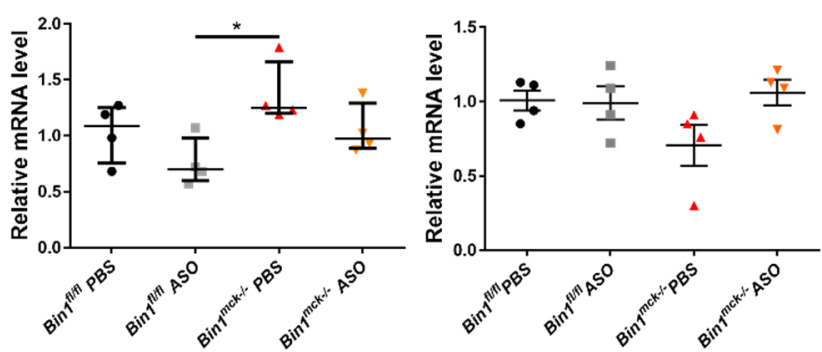

\section{Supplemental Figure S8.}


Supplemental Table S1.

$\begin{array}{ccc}\text { Gene } & \text { Forward primer } & \text { Reverse primer } \\ \text { Rpl27 } & \text { AAGCCGTCATCGTGAAGAACA } & \text { CTTGATCTTGGATCGCTTGGC } \\ \text { Bin1 } & \text { GATTCCTTTCCAGAACCCAG } & \text { AAAATTCTCCGGGAAGACGC } \\ \text { Dnm2 } & \text { ACCCCACACTTGCAGAAAAC } & \text { CGCTTCTCAAAGTCCACTCC } \\ \text { Myh7 } & \text { CTACAGGCCTGGGCTTACCT } & \text { TCTCCTTCTCAGACTTCCGC } \\ \text { Myh2 } & \text { ATCCAAGTTCCGCAAGATCC } & \text { TTCGGTCATTCCACAGCATC } \\ \text { Myh1 } & \text { ATGAACAGAAGCGCAACGTG } & \text { AGGCCTTGACCTTTGATTGC } \\ \text { Myh4 } & \text { AGACAGAGAGGAGCAGGAGAGTG } & \text { CTGGTGTTCTGGGTGTGGAG } \\ \text { Ppargc1a } & \text { GGAATGCACCGTAAATCTGC } & \text { TTCTCAAGAGCAGCGAAAGC } \\ \text { Map1/c3a } & \text { CTATGAACAGGAGAAGGATGAAG } & \text { ACTCAGAAGCCGAAGGTT } \\ \text { Map1/c3b } & \text { CGTCCTGGACAAGACCAAGT } & \text { ATTGCTGTCCCGAATGTCTC } \\ \text { Sqstm1 } & \text { CCTTGCCCTACAGCTGAGTC } & \text { CACACTCTCCCCCACATTCT }\end{array}$

